REVISTA DE DERECHO UNED, NÚM. 23, 2018

\title{
EL CONTENIDO JURÍDICO DEL CONCEPTO DEL LIBRE DESARROLLO DE LA PERSONALIDAD CON REFERENCIA ESPECIAL A LOS SISTEMAS CONSTITUCIONALES ALEMÁN Y ESPAÑOL ${ }^{1}$
}

\author{
THE LEGAL CONTENT OF THE CONCEPT \\ OF THE FREE DEVELOPMENT OF THE PERSONALITY \\ WITH PARTICULAR REFERENCE TO THE GERMAN \\ AND SPANISH CONSTITUTIONAL ORDER
}

\section{MARIUSZ RYSZARD KOSMIDER}

Doctorando de Derecho de Unión Europea en la Escuela Internacional de Doctorado de la Universidad Nacional de Educación a Distancia

$(\mathrm{UNED})^{2}$

Resumen: Aunque el concepto del libre desarrollo de la personalidad se posiciona distintamente en los ordenamientos constitucionales alemán y español, respectivamente como derecho fundamental y como principio rector, el contenido del mismo no tiene por qué diferenciarse. Contextualizando estas referencias con otras legislaciones nacionales, disposiciones internacionales, con la jurispruden-

${ }^{1}$ El presente estudio acompaña a la investigación para la tesis doctoral en Derecho de Unión Europea realizada en la Escuela Internacional de Doctorado de la UNED titulada "El derecho al libre desarrollo de la personalidad en la Sociedad de la Información y del Conocimiento» bajo la dirección de la Profesora Dra. D. ${ }^{a}$ María Yolanda Gómez Sánchez, Catedrática de Derecho Constitucional, Catedrática Jean Monnet, ad personam y Dra. Cristina Elías Méndez, Profesora Titular de Derecho Constitucional, Profesora Jean Monnet.

${ }^{2}$ Graduado de Máster Universitario en Derecho de Unión Europea (LL.M. Eur) y de Máster en Economía Aplicada ambos por la UNED. Graduado de Máster Universitario en Democracia y Gobierno por la Universidad Autónoma de Madrid. Magíster de Derecho por la Universidad de Wroclaw (Polonia). 
cia, la doctrina y las reflexiones extrajurídicas para la interpretación lingüística (literal), el artículo busca descubrir los rasgos universales del dicho concepto y desglosar su contenido con el fin de ofrecer una acepción jurídica vasta adaptable comúnmente en cualquier sistema legal que reconozca el valor de la composición libre y plena de la personalidad del individuo, así como también evaluar las ventajas sociales de la protección jurídica explicita del bien (valor) del libre desarrollo personal. Se llega a la conclusión que el significado del concepto del libre desarrollo de la personalidad a parte de relacionarse con la libertad de acción del sujeto, es decir de expresarse libremente en la esfera externa y de iniciación y mantenimiento de relaciones sociales exentas de intromisiones, impedimentos y autocensura (la protección de la vida privada y social), consiste en poder desarrollar libremente y plenamente la esfera interna de lo psíquico, intelectual, cognitivo, artístico, emocional y espiritual de la persona.

Palabras clave: Libre desarrollo de la personalidad, Dignidad humana, Constitución Española, Ley Fundamental alemana, Derechos fundamentales.

Abstract: Although the concept of the free development of the personality is distinctly positioned in the German and Spanish constitutional order, respectively as the fundamental right and the guiding principle, its meaning does not have to be differentiated. Contextualizing these references within other national legislations and international law for the systematic interpretation and within jurisprudence, doctrine and extrajudicial reflections for the linguistic (literal) interpretation, the article seeks to discover the universal features of this concept and break down its content trying to give a vast and common juridical meaning suitable for any legal system that recognizes the importance of the free and complete composition of the personality of the individual, as well as to evaluate the social advantages of the explicit legal protection of the good (value) of the free personal development. It is concluded that the meaning of the concept of the free development of the personality besides relating itself to the freedom of action of the subject, i.e. the right to express yourself freely in the outer sphere and the initiation and maintenance of social relationships free of interferences, impediments and self-censorship (the respect for private and social life), consists of the right to the development of the inner (personal) sphere of the psychic, intellectual, cognitive, artistic, emotional and spiritual nature.

Keywords: Free development of personality, Human dignity, German Basic Law, Spanish Constitution, Fundamental rights. 
Recepción original: 27/04/2018

Aceptación original: 09/10/2018

Sumario: I. Los preceptos de las constituciones alemana y española relativos al desarrollo personal.-II. Métodos de interpretación jurídica aplicados: interpretación lingüística (literal) y sistemática.III. Contextos jurídicos nacionales e internacionales del concepto del libre desarrollo personal.-IV. El entorno jurídico alemán.-V. El entorno jurídico español. El libre desarrollo personal y la dignidad humana.-VI. Conclusiones.-VII. Bibliografía.

\section{LOS PRECEPTOS DE LAS CONSTITUCIONES ALEMANA Y ESPAÑOLA RELATIVOS AL DESARROLLO PERSONAL}

Ambos textos constitucionales, la Ley Fundamental de la República Federal de Alemania de 1949 (GG: Grundgesetz) y la Constitución Española de 1978 (CE), introducen textualmente el concepto del libre desarrollo de la personalidad del ser humano, elevando de tal modo al nivel legal más alto su significado para los sistemas jurídicos correspondientes, con repercusiones sustanciales para todo ciudadano implicado en dichos ordenamientos.

La Ley Fundamental alemana concede un gran peso al derecho al libre desarrollo (desenvolvimiento) de la personalidad del individuo de tal manera que justamente después de exponer en el Artículo 1 GG la norma troncal del sistema alemán de los derechos fundamentales que garantiza la protección de la dignidad humana, el sucesivo Artículo 2.1 GG ordena lo siguiente:

Jeder hat das Recht auf die freie Entfaltung seiner Persönlichkeit, soweit er nicht die Rechte anderer verletzt und nicht gegen die verfassungsmäßige Ordnung oder das Sittengesetz verstößt.

Toda persona tiene el derecho al libre desarrollo de su personalidad siempre que no viole los derechos de otros ni atente contra el orden constitucional o la ley moral. ${ }^{3}$

La norma constitucional española que hace referencia al concepto del libre desarrollo de la personalidad se encuentra bajo el Tí-

${ }^{3}$ Si se citan las disposiciones de la Ley Fundamental alemana en español provienen de la traducción por Ricardo García Macho y Karl-Peter Sommermann accesible en la página de Deutscher Bundestag https://www.btg-bestellservice.de/ pdf/80206000.pdf. Si no hay otra indicación el acceso a los recursos electrónicos citados a lo largo del artículo se confirmó los días 08-09.02.2018.

(c) UNED. Revista de Derecho UNED, núm. 23, 2018 
tulo I De los derechos y deberes fundamentales en el artículo $10 \mathrm{CE}$. Al citar la disposición de manera íntegra, se proclama lo siguiente:

1. La dignidad de la persona, los derechos inviolables que le son inherentes, el libre desarrollo de la personalidad, el respeto a la ley y a los derechos de los demás son fundamento del orden político y de la paz social.

2. Las normas relativas a los derechos fundamentales y a las libertades que la Constitución reconoce se interpretarán de conformidad con la Declaración Universal de Derechos Humanos y los tratados y acuerdos internacionales sobre las mismas materias ratificados por España.

De esta manera, ambos textos constitucionales lo reconocen e implementan, incluso destacan por la ubicación eminente, el concepto mismo de el libre desarrollo de la personalidad, aunque lo posicionan en los sistemas concernientes de modo esencialmente distinto. Por la razón del posicionamiento tan diverso del concepto en cuestión los efectos jurídicos pueden diferir entre los sistemas y las prácticas jurisprudenciales. Sin embargo, al adelantarse, se puede concluir que la acepción propia atribuible a la noción jurídica en sí de el libre desarrollo de la personalidad pueda llevar un contenido (sentido) común para los ordenamientos referentes y, yendo más allá, aplicable para otros sistemas jurídicos.

Dar amparo jurídico al libre desarrollo (la libre composición) de la personalidad del individuo, por un lado, conlleva cierta naturaleza de derecho negativo (libertad) que obliga a los terceros, incluso al Estado, a desistir de injerencias perjudiciales para el desarrollo pleno y armonioso del sujeto. Por otro lado, debe implicar también el apoyo activo al libre desarrollo de la persona en cuanto a la esfera interna de la misma que deba provenir de las instituciones estatales y de la sociedad que la rodea, como un derecho positivo, hasta permitirle al ciudadano presentar determinadas reclamaciones. Ambos aspectos de la función jurídica del concepto del libre desarrollo de la personalidad coinciden lógicamente y materialmente con la protección de la dignidad humana, el valor conductor e indiscutible del Estado democrático de derecho y la Unión Europea como una organización supranacional.

\section{MÉTODOS DE INTERPRETACIÓN JURÍDICA APLICADOS: INTERPRETACIÓN LINGÜÍSTICA (LITERAL) Y SISTEMÁTICA}

El contenido material de la expresión el libre desarrollo de la personalidad presente en diferentes sistemas normativos no ha de ser 
necesariamente inequívoco ${ }^{4}$, pero si hubiera controversias al respecto, esas afectarían en el mismo grado a cualquier ordenamiento legal, ya sea nacional o internacional.

El trabajo presentado afronta la cuestión de deducir o más bien determinar en el proceso interpretativo el significado jurídicamente justificable de la locución libre desarrollo de la personalidad, incluida en varios textos legislativos, sobre todo constitucionales, utilizando ciertos métodos aceptados por las ciencias jurídicas.

En primer lugar, nos centramos en la interpretación literal ${ }^{5}$, llamada también lingüística, textual o gramatical. Así, «la interpretación lingüística sería aquella relacionada con la determinación del significado de ciertas expresiones lingüísticas (orales o escritas) $»^{6}$.

En segundo lugar, es imprescindible revisar distintos ordenamientos jurídicos y contextos legislativos concretos en los cuales aparece la noción de libre desarrollo de la personalidad para acercarse al sentido y contenido de la misma, lo que sirve para conseguir una interpretación sistemática del término, suponiendo que el legislador utiliza la misma locución en el mismo sentido a lo largo de todo el texto normativo, incluso consecuentemente en todo el sistema jurídico. Después, desde el contexto y las relaciones en los que el legislador incluye dicho término se puede deducir la acepción atribuida por el legislador al mismo.

Para el tema abordado fue determinante que la interpretación lingüística de la locución libre desarrollo de la personalidad conforme al entendimiento usual léxico, de reflexiones doctrinales, argumentaciones judiciales y posiciones de distintas disciplinas no jurídicas avalada por la observación de los diferentes contextos legislativos en los cuales aparece dicha expresión apunta hacia una comprensión de la misma mucho más extensa que la reducida a la libertad de acción (expresiones externas) del sujeto, la posición dominante en la jurisprudencia alemana, y va incluso hasta las reclamaciones del in-

${ }^{4}$ Acerca de la interpretación de las normas jurídicas en general, y minuciosamente en relación con los problemas de interpretación del lenguaje jurídico (ambigüedades, imprecisiones o vaguedades) véase: Santiago Nino, C. (2003). Introducción al análisis del derecho. Buenos Aires. Astrea, pp. 245 y siguientes.

5 Poggi, F. (2007). "Significado literal: una noción Problemática», DOXA, Cuadernos de Filosofía del Derecho, 30, p. 618 (https://dialnet.unirioja.es/ ejemplar/202526, acceso el 19.06.2018).

6 Martínez Zorrilla, D. (2010). Metodología jurídica y argumentación. Madrid: Marcial Pons, p. 45, citado por Quispe Astoquilca, C.L. (2011). «La interpretación constitucional», Papeles de Teoría y Filosofía del Derecho. Núm. 13, p. 2 (http:// portal.uc3m.es/portal/page/portal/instituto_derechos_humanos/working_papers - acceso el 19.06.2018). 
dividuo relacionadas con el desarrollo de la esfera interna (psíquica) de la persona (las obligaciones positivas del Estado).

Con todo, la combinación de palabras libre desarrollo de la personalidad tiene el carácter de una locución reconocida como tal por distintos campos del conocimiento científico y humanístico. El significado de las palabras conjuntas, una locución o frase de un texto, precepto o enunciado normativo o de la disposición entera, teniendo en cuenta las reglas gramaticales y sintácticas, puede ir más allá de la simple combinación de acepciones de cada palabra por separado, es decir trae una acepción íntegra derivada del uso. Así, la noción libre desarrollo de la personalidad es bastante compleja, constituye un conglomerado íntegro de palabras, por lo que para atribuirle un significado ya no basta la comprensión léxica de cada palabra por separado, puesto que dicho constructo en sí está sujeto a investigaciones y reflexiones de diversas ciencias y distintos campos de conocimiento. La acepción de dicha locución en el lenguaje jurídico no se aparta de estas correspondencias. Por consiguiente, el alcance de aplicación de una norma jurídica que contiene dicho término depende inapelablemente de la comprensión del mismo por las distintas disciplinas, incluidas las no jurídicas. La comprensión correcta del concepto en cuestión es de importancia clave desde la perspectiva de la interpretación jurídica ya que en diferentes ordenamientos constitucionales se declara como un bien (un valor) autónomo protegido jurídicamente de manera directa y explicita (bajo el amparo de un derecho fundamental) y en otras ocasiones forma un objetivo (en el derecho a la educación) o una directriz (la moderación de carga en trabajo de jóvenes para no obstaculizar el desarrollo personal). Así, pues, para resolver un caso concreto en el proceso de decisión judicial o argumentación jurídica hay que reconstruir la acepción de dicha locución con el fin de decidir si la protección de un precepto determinado que la contiene sirve o no en tal asunto.

Precisar el contenido del concepto de libre desarrollo de la personalidad permitirá o al menos facilitará obtener una interpretación consistente y fiable de las disposiciones normativas (preceptos, enunciados $\mathrm{u}$ oraciones) en las cuales aparece dicho término, pues, «el Derecho no es simplemente algo dado a priori en las leyes, en las sentencias, etc. ... sino la práctica consistente en atribuir sentido a estos materiales. $\aleph^{7}$ Así, para lograr una interpretación jurídicamente correcta de una disposición de algún texto normativo hay que emprender una «actividad que consiste en determinar el signi-

${ }^{7}$ Atienza, M. (2003). El sentido del Derecho. Barcelona: Ariel, p. 267. 
ficado» de la misma. A esta actividad se la denomina interpretación textual $^{8}$. La interpretación textual de un precepto consiste en «dos conjuntos correlacionados de operaciones», se trata de la interpretación sintáctica y semántico-pragmática ${ }^{9}$. La primera reside en identificar y entender la estructura lingüístico-gramatical de la frase normativa ${ }^{10}$, lo que permite descubrir eventuales problemas formales en comprender el mensaje del legislador. La segunda fase, la interpretación semántico-pragmática aborda dos aspectos: «determinar el significado de las concretas expresiones (palabras y locuciones) utilizadas en la disposición; y, por otro lado, determinar el significado de conjunto de la disposición» ${ }^{11}$. En la búsqueda del significado fiable, correcto y justificado de las palabras o locuciones y la disposición entera hay que dirigirse, entre otros, hacia «el intertexto de la disposición, constituido por todos los textos normativos [...] y no-normativos (dogmático-jurídicos, etnológicos, filosóficos, jurisprudenciales, literarios, político-económicos, médicos, teológicos, históricos, etc.), a los que el intérprete considere que debe y/o puede recurrir al interpretar la disposición» y a "Los específicos contextos extralingüísticos de la disposición (culturales, institucionales, políticos, sociales, históricos, etc.)...» ${ }^{12}$. Merece la pena destacar que, aparte de la función referente a aportar a la atribución de significado a palabras o nociones ya presentes en el lenguaje jurídico o normativo, las reflexiones desde fuera del ámbito jurídico, sobre todo relacionadas con el ser humano y su entorno social, ambiental o económico, sirven para identificar ciertos bienes o valores que deban someterse al amparo de la ley por su relevancia para el ser humano particular, la sociedad o el futuro de ellos, bienes y valores dignos de protección jurídica aún no reconocida.

En concreto, para poder conseguir un entendimiento objetivo y completo de la expresión libre desarrollo de la personalidad sirven los métodos de interpretación jurídica: lingüísticos (literales, gramaticales), pragmáticos, valorativos, sistemáticos, históricos, teleológicos, etc. (las reglas de interpretación de primer grado ${ }^{13}$ ), que exigen en su caso referencias tanto a los propios textos normativos, las sentencias

${ }^{8}$ Chiassoni, P. (2011). Técnicas de interpretación jurídica. Breviario para juristas. Madrid: Marcial Pons, pp. 56-57.

${ }^{9}$ Chiassoni, ibidem, p. 58.

${ }^{10}$ Chiassoni, ibídem, pp. 59-60.

${ }^{11}$ Chiassoni, ibídem, p. 66.

12 Chiassoni, ibídem, p. 66.

13 Atienza, op. cit., p. 269. Véase también: Anchondo Paredes, V.E. (2012). «Métodos de interpretación jurídica». Quid Iuris, año 6, vol. 16 (https://revistascolaboracion.juridicas.unam.mx/index.php/quid-iuris/issue/view/1069 - acceso el 19.06.2018). 
judiciales y reflexiones doctrinales como a las consideraciones meta (extra) jurídicas.

La concepción per se que se materializa en el término de libre desarrollo de la personalidad en los documentos constitucionales citados: alemán y español se enraíza efectivamente en las reflexiones de la jurisprudencia (a continuación se citarán las sentencias de los tribunales constitucionales alemán y español) y la doctrina propias de dichos ordenamientos, pero también en las que se desarrollan fuera de ambos ámbitos nacionales, hasta que su comprensión se ancla en el pensamiento universal en torno a los derechos humanos. Como se ha dicho, la idea y el sentido jurídico de la expresión libre desarrollo de la personalidad del ser humano se arraiga en las consideraciones extra y meta jurídicas, haciendo referencia a otras áreas de reflexión humanista, tales como la psicología, antropología, filosofía, pedagogía o ciencias de educación. De todo ello se desprende la interrelación de este concepto con otros saberes y fines y muestra la importancia de la protección del libre desarrollo humano, tanto para el individuo como para la sociedad en su conjunto, y le dan el apoyo legal material e institucional.

En este contexto, estas páginas pretenden poner énfasis en el entendimiento del propio concepto de libre desarrollo personal, como el punto de partida para las eventuales aplicaciones en cualquier ordenamiento jurídico que reconoce explícitamente o implícitamente el significado de este concepto, o bien a través de la promulgación de un claro derecho fundamental o la proclamación de cualquier otra figura jurídicamente relevante, ya sea un precepto interpretativo, una orientación valorativa o un principio rector.

\section{CONTEXTOS JURÍDICOS NACIONALES E INTERNACIONALES DEL CONCEPTO DEL LIBRE DESARROLLO PERSONAL}

Con la intención de precisar el significado de la locución libre desarrollo de la personalidad se presentarán a continuación referencias al derecho internacional y a textos constitucionales nacionales. Debemos insistir en que la acepción jurídica de la expresión libre desarrollo de la personalidad no puede limitarse a la mera libertad de acción (manifestaciones hacia afuera) del sujeto sino que atañe también al desarrollo de la esfera interna (psíquica) de la persona. De este modo, antes de sumergirse entre las consideraciones detalladas de la doctrina y jurisprudencia alemanas y españolas intentaremos 
colocar el concepto de libre desarrollo personal en una mayor perspectiva jurídica.

En el ámbito de la Unión Europea, la Carta de los Derechos Fundamentales de la Unión Europea (CDFUE), no contiene ninguna referencia expresa al concepto de libre desarrollo de la personalidad del individuo, aunque sí su Preámbulo apunta a la persona como el destinatario de la acción de la propia Unión Europea destacando que "Al instituir la ciudadanía de la Unión y crear un espacio de libertad, seguridad y justicia, sitúa a la persona en el centro de su actuación.» Con relación específica al trabajo de los jóvenes (art. 32 CDFUE) se proclama la protección contra el trabajo dañino para el desarrollo psíquico y moral del joven. Así, podríamos preguntarnos qué representa esta ausencia de la mención expresa al libre desarrollo de la personalidad en la Carta; estimamos que aunque hubiera sido preferible contar con una cita literal al libre desarrollo de la personalidad en la Carta, otras disposiciones en los Tratados y en el Derecho derivado suplen esta ausencia. Especialmente significativa es a este respecto el reconocimiento de la dignidad de la persona en el artículo 1 de la propia Carta.

La dignidad de la persona, cuya protección e inviolabilidad puede considerarse como un parámetro esencial dentro de la CDFUE, representa el reconocimiento de la naturaleza permanente e igual de todo ser humano ${ }^{14}$. Por lo contrario, la personalidad en el sentido psicológico es la característica más cambiante ${ }^{15}$, supone la creciente consecución (adquisición o persecución) de la autonomía y la autoestima del individuo y la permanente transformación de la percepción de sí mismo, desde las edades tempranas hasta las tardías, y requiere la garantía contra intromisiones y el apoyo positivo de los poderes públicos para lograr un entorno socio-jurídico en el que el ser humano pueda desarrollarse plenamente.

En el ámbito del Consejo de Europa, debemos igualmente decir que, como ya sucedía en el caso de la CEDFUE, tampoco el Conve-

${ }^{14}$ Como lo explica el Tribunal Constitucional Federal alemán (TCFA, Bundesverfassungsgericht) «Donde hay vida humana, la dignidad humana le corresponde; no es decisivo si el portador es consciente de esta dignidad y es capaz de defenderla. Bastan las capacidades potenciales atribuidas desde el principio al ser humano para dar lugar a la dignidad humana.» (Traducción propia. Se citarán las primeras palabras de la versión original de la frase traducida para permitir ubicarla en el texto fuente. „Wo menschliches Leben existiert, kommt ihm Menschenwürde zu [...]» (BVerfGE 39, 1) [BVerfGE: art.1/ la Sentencia del TCFA].

15 Santana Ramos, E.M. (2014). «Las claves interpretativas del libre desarrollo de la personalidad». Cuadernos Electrónicos de Filosofía del Derecho,núm. 29, p. 103 (https://ojs.uv.es/index.php/CEFD/issue/view/277). 
nio Europeo de los Derechos Humanos de los Miembros del Consejo de Europa incluye referencias directas al libre desarrollo de la personalidad aunque, tanto la antigua Comisión Europea de los Derechos Humanos en sus informes y como el Tribunal Europeo de los Derechos Humanos (TEDH) en sus sentencias han confirmado que el derecho al libre desarrollo deriva de la protección otorgada por el Artículo $8 \mathrm{CEDH}$ en relación con el respeto de la vida privada. El apartado 1 del artículo 8 proclama lo siguiente:

Toda persona tiene derecho al respeto de su vida privada y familiar, de su domicilio y de su correspondencia.

Ya en el año 1977, la Comisión precisó lo siguiente (Informe de 12 de julio 1977, Bruggemann and Scheuten c. República Federal de Alemania, Párrafos 55-57):

El derecho al respeto de la vida privada tiene un alcance tal que garantiza al individuo una esfera dentro de la cual puede dedicarse libremente al desarrollo y al cumplimiento de su personalidad. A este efecto, también debe tener la posibilidad de establecer relaciones de diversos tipos, incluso sexuales, con otras personas. En principio, por lo tanto, cada vez que el Estado establece normas para el comportamiento del individuo en esta esfera, interfiere con el respeto a la vida privada y tal interferencia debe estar justificada a la luz del Artículo 8 (2). Sin embargo, hay límites para la esfera personal. Si bien una gran parte de la ley existente en un Estado determinado tiene algún efecto inmediato o remoto sobre la posibilidad del individuo de desarrollar su personalidad haciendo lo que quiere hacer, no se puede considerar que todos estos efectos constituyan una interferencia con la vida privada en el sentido del Artículo 8 del Convenio. De hecho, como ya lo ha demostrado la jurisprudencia anterior de la Comisión, la reclamación de respeto a la vida privada se reduce automáticamente en la medida en que el individuo pone su vida privada en contacto con la vida pública o en estrecha relación con otros intereses protegidos. Así, la Comisión ha considerado que el concepto de la vida privada en el Artículo 8 era más amplio que la definición dada por numerosos autores anglosajones y franceses, a saber, el «derecho a vivir de manera cómo se quiere, protegido de la publicidad», que también comprende, «hasta cierto punto, el derecho a establecer y desarrollar relaciones con otros seres humanos, especialmente en el campo emocional para el desarrollo y la realización de la propia personalidad». ${ }^{16}$

Lo anterior se inscribe en la línea jurisprudencial del Tribunal Constitucional alemán en cuanto al reconocimiento de la libertad de acción (hacer lo que se quiera hacer) dentro del derecho al libre de-

${ }^{16} \mathrm{Si}$ no se indica lo contrario se citan sentencias del TEDH e informes de la $\mathrm{CEDH}$ en traducción de inglés propia del autor. 
sarrollo de la personalidad. Asimismo, destaca el alcance ampliado del concepto de la vida privada tratado por el artículo $8 \mathrm{CEDH}$. Sin duda ninguna, la protección de la autonomía y de la de vida privada, sin intromisiones, sin estar perseguido, observado o grabado ${ }^{17}$, es una condición imprescindible para poder autodeterminarse y desarrollarse. Las eventuales restricciones e injerencias, cualquiera que sea su naturaleza y proveniencia, obstaculizan estos objetivos y cuando fueran ilegítimas, injustificadas o desproporcionadas no resultan aceptables ${ }^{18}$.

En definitiva, el TEDH confirma que, entre otras finalidades, el artículo $8 \mathrm{CEDH}$ sirve para asegurar el desarrollo, sin injerencias externas, de la personalidad de cada individuo en la relación con sus semejantes, luego existe tal esfera protegida de vida privada que engloba la integridad física y moral y la identidad de una persona, cuya protección es vital para permitir a la persona el libre desarrollo (Peck c. Reino Unido de 28 de enero de 2003, Párrafo 57). En la sentencia Botta c.Italia de 24 febrero 1998 el TEDH (Resumen y Párrafo 32) afirmó que:

Vida privada incluye la integridad física y psicológica de la persona que es la garantía otorgada por el artículo 8 del Convenio, cuyo objetivo principal es garantizar el desarrollo, sin interferencia externa, de la personalidad de cada individuo en sus relaciones con otros seres humanos.

Entonces, el alcance del concepto de la vida privada no se limita a lo privado en el sentido estricto, reducido al domicilio $\mathrm{u}$ otro «circulo interno en el cual el individuo puede vivir su vida personal como él elija y excluirla totalmente del mundo exterior no incorporado en ese círculo. Respeto a la vida privada también debe comprender hasta cierto punto el derecho a establecer y desarrollar relaciones con otros seres humanos» (Niemietz c. Alemania de 16 diciembre 1992, Párrafo 29). Por tanto, la vida privada incluye igualmente la vida social de la

17 Sobre la interceptación de llamadas telefónicas del carácter privado provenientes de locales profesionales decidió el TEDH en la Sentencia Halford contra Reino Unido de 25 de junio de 1997 y sobre las grabaciones de los detenidos en las instalaciones de la policía en $P G$ y JH contra Reino Unido de 25 de diciembre de 2001.

${ }_{18}$ Este artículo se centra en denotar el concepto del libre desarrollo de la personalidad, por esas razones no se pueden tratar con la misma profundidad otras materias relacionadas con el derecho al libre desarrollo de la personalidad u otra figura jurídica que incluye este concepto. En cuanto al análisis más profundo de las cuestiones de autonomía, identidad e integridad de la persona en el contexto del CEDH que están en un vínculo estrecho con el tema véase: Marshall, J. (2009). Personal Freedom Through Human Right's Law. Autonomy, Identity and Integrity under the European Convention on Human Rights. Martinus Nijhoff Publishers. 
persona, es decir la esfera y los lugares de interacciones entre el individuo y los demás, ya sean en público (PG y JH c. Reino Unido de 25 de diciembre de 2001, párrafo 57) o en privado.

Como hemos indicado, la jurisprudencia del TEDH es coincidente con la jurisprudencia dominante alemana acerca de la libertad de acción, en relación con el significado del concepto del libre desarrollo personal en la faceta más íntima, intelectual o emocional del individuo. Así, en relación con el reconocimiento y la protección del libre desarrollo de la personalidad se abogará por orientarse más allá de asegurar meramente la libertad de manifestaciones externas o la construcción y el mantenimiento de relaciones personales incluso en público (los lazos sociales), que, sin lugar a dudas, son condicionantes irreducibles del libre desarrollo individual, para llegar a reclamar al Estado y al legislador que establezca y mantenga el entorno socio-jurídico propicio al desarrollo de dicha zona interna de lo psíquico, intelectual, cognitivo, axiológico, emocional, espiritual de la persona.

En el asunto von Hannover c. Alemania de 24 de junio 2004 el TEDH vuelve al aspecto de la vida libre de publicidad y persecución periodística y de este modo a la libertad de manifestarse libremente, en relación con la toma y publicación de fotografías sin consentimiento del interesado que incluyen las escenas de vida cotidiana, así de actividades de carácter estrictamente privado, reafirmando la protección de la zona de actuaciones del individuo y sus interacciones con los demás incluso en público. El derecho a expresarse libremente, asimismo en los lugares públicos, sin sentirse perseguido, constituye uno de los fundamentos esenciales de una sociedad democrática y una de las condiciones primordiales para el progreso y el desarrollo de cada persona. Así, el TEDH afirma una y otra vez que la circunstancia de libertad efectiva en la vida del individuo juega el papel fundamental en el libre y pleno desarrollo de la personalidad, hasta constituir un rasgo inherente al derecho que lo protege y garantiza.

En cuanto al ámbito de actuación de los poderes públicos la jurisprudencia indica que éstos tienen obligaciones positivas de protección inherentes al respeto efectivo de la vida privada e deben implementar las medidas necesarias para asegurar la eficacia de la realización de los derechos y libertades implicados (von Hannover $c$. Alemania de 24 de junio 2004, párrafo 57). ${ }^{19}$ En Botta c. Italia de 24

19 De modo similar las sentencias: X e Y c. Países Bajos de 26 marzo 1985, Stjerna c. Finlandia de 25 noviembre de 1994, Stubbings and Others c. the United Kingdom de 22 de octubre de 1996 y la decisión Verliere contra Suiza de 28 de junio de 2001. 
febrero 1998 (Párrafo 33) el TEDH formula esta tesis de la siguiente manera:

Si bien el objeto esencial del artículo 8 es proteger al individuo contra la injerencia arbitraria por parte de las autoridades públicas, dicho artículo no solo obliga al Estado a abstenerse de tal interferencia: además de este compromiso negativo, puede tener obligaciones positivas inherentes al respeto efectivo de la vida privada o familiar. Estas obligaciones pueden implicar la adopción de medidas destinadas a garantizar el respeto de la vida privada, incluso en el ámbito de las relaciones de las personas entre sí.

Trasladándose al terreno del derecho al libre desarrollo de la personalidad con la referencia al desarrollo interno de la persona es importante insistir en la reiterada conclusión del TEDH acerca de que la protección de libertad, cualquiera que sea la naturaleza de esta, exige también ciertas obligaciones por parte del poder público. Si partimos de que el derecho al libre desarrollo de la personalidad cubre la libertad de obtener informaciones y conocimientos para fomentar este desarrollo, hay que preguntarse por la existencia de medidas jurídicas y prácticas concretas y efectivas que lo hagan posible y alcanzable a todo ciudadano ${ }^{20}$.

Todavía en el ámbito del Consejo de Europa, encontramos referencias explícitas al libre desarrollo personal en la Carta Social Europea (Estrasburgo, 3 de mayo de 1996) donde se menciona dicho concepto en varios contextos. Así, el artículo 7 titulado Derecho de los niños y adolescentes a protección, lo pone en su punto 4 en relación con las restricciones sobre la duración y organización de «la jornada laboral de los trabajadores menores de 18 años para adecuarla a las exigencias de su desarrollo y, en particular, a las necesidades de su formación profesional». Por su parte, el artículo 17 bajo el título $D e$ recho de los niños y adolescentes a protección social, jurídica y econó-

${ }^{20}$ En cuanto a las obligaciones positivas del Estado véanse: Akandji-Kombe, J.-F. (2007). Positive obligations under the European Convention on Human Rights. A guide to the implementation of the European Convention on Human Rights. Human rights handbooks, No. 7. Council of Europe; Mowbray, A. (2004). The Development of Positive Obligations under the European Convention on Human Rights by the European Court of Human Rights. Hart Publishing; Klatt, M. (2011), "Positive obligations under the European Convention on Human Rights». Zeitschrift für ausländisches öffentliches Recht und Völkerrecht (ZaöRV), núm, 71 pp. 691 y siguientes (http://www.zaoerv.de/71_2011/vol71.cfm); Tomlinson, H. (2012). «Positive Obligations under the European Convention on Human Rights». Matrix Chambers (https:// adminlaw.org.uk/wp-content/uploads/SC-2012-by-Tomlinson-QC.docx); Viljanen, J. ( $\sin$ fecha). State Obligations to Protect the Right to Respect for Private Life under Article 8 of the ECHR and the Challenge of the Internet. The Human Rights Institute of the University of Iceland (http://mhi.hi.is/internet_responsibility). Acceso a los textos el 29.06.2018. 
mica indica las circunstancias «Para garantizar el ejercicio efectivo del derecho de los niños y los adolescentes a crecer en un medio que favorezca el pleno desarrollo de su personalidad y de sus aptitudes físicas y mentales». El artículo 14 llamado Derecho a los beneficios de los servicios sociales trata del «ejercicio efectivo del derecho a beneficiarse de los servicios sociales», cuyo uno de los fines es «fomentar u organizar servicios que, utilizando los métodos de un servicio social, contribuyan al bienestar y al desarrollo de los individuos y de los grupos en la comunidad, así como a su adaptación al medio o entorno social». El artículo 20 sobre el Derecho a la igualdad de oportunidades $y$ de trato en materia de empleo y de profesión, sin discriminación por razón del sexo acude a "las medidas apropiadas para asegurar o promover» la aplicación del derecho del que se trata con el enfoque en «el desarrollo profesional». En cuanto al desarrollo de los individuos ya los contextos indicados permiten concluir que se trata del desarrollo de las calidades internas de la persona.

También la Declaración Universal de Derechos Humanos de 1948, en el artículo 22, afirma en que «Toda persona, como miembro de la sociedad, tiene derecho a... la satisfacción de los derechos económicos, sociales y culturales, indispensables a su dignidad y al libre desarrollo de su personalidad.» y, a continuación, el artículo 26.2 declara que «La educación tendrá por objeto el pleno desarrollo de la personalidad humana...». De un modo semejante el Pacto Internacional de Derechos Económicos Sociales y Culturales de 1966, en el artículo 13.1, aúna «el pleno desarrollo de la personalidad humana y del sentido de su dignidad» con el derecho a la educación.

La Convención sobre los Derechos del Niño de 20 de noviembre de 1989, reconoce el mérito del libre desarrollo personal subrayando ya en el Preámbulo «que el niño, para el pleno y armonioso desarrollo de su personalidad, debe crecer en el seno de la familia, en un ambiente de felicidad, amor y comprensión» e indicando "la importancia de las tradiciones y los valores culturales de cada pueblo para la protección y el desarrollo armonioso del niño». El artículo 29.1.a de la misma insiste en que "la educación del niño deberá estar encaminada a desarrollar la personalidad, las aptitudes y la capacidad mental y física del niño hasta el máximo de sus posibilidades».

En las constituciones europeas encontramos también ejemplos reseñables. Así, en la Constitución griega del año 1975 (art. 5.121);

21 «All persons shall have the right to develop freely their personality and to participate in the social, economic and political life of the country, insofar as they do not infringe the rights of others or violate the Constitution and the good usages.» (http://www.wipo.int/wipolex/es/text.jsp?file_id=182913, sin traducción). 
en la Constitución portuguesa, la cual relaciona el concepto del libre desarrollo de la personalidad con la educación, la cultura y la ciencia (art. 73.222); en la Constitución de la República Italiana donde se establece que «La República reconoce y garantiza los derechos inviolables del hombre, tanto como individuo como en el seno de las formaciones sociales donde se desarrolla su personalidad...» (art. 2), y añade que «Es obligación de la República suprimir los obstáculos de orden económico y social que, limitando de hecho la libertad y la igualdad de los ciudadanos, impidan el pleno desarrollo de la persona humana» (art. 3.2).

En el entorno latinoamericano, a nivel supranacional, por ejemplo, el Protocolo Adicional a la Convención Americana sobre Derechos Humanos en Materia de Derechos Económicos, Sociales y Culturales, «Protocolo De San Salvador», reconoce la importancia del desarrollo personal en el contexto de la educación (art. 13.2 ${ }^{23}$ ) y la protección de las personas con discapacidad (art. 18 ${ }^{24}$ ).

Entre los ordenamientos nacionales de este continente, la Constitución colombiana de 1991, en su artículo 16, establece explícitamente el derecho al libre desarrollo de la personalidad «sin más limitaciones que las que imponen los derechos de los demás y el orden jurídico». De manera semejante, la Constitución de Ecuador, en su artículo 66, lo reconoce como un derecho independiente y primordial, añadiéndolo también en relación a la educación (art. 27). Asimismo, es la tarea del sistema nacional de educación (art. 343) «el desarrollo de capacidades y potencialidades individuales y colectivas de la población, que posibiliten el aprendizaje, y la generación y utilización de conocimientos, técnicas, saberes, artes y cultura.», lo que coincide con la responsabilidad general del Estado de «Establecer políticas e implementar formas de enseñanza para el desarrollo

22 «O Estado promove a democratização da educação e as demais condições para que a educação, realizada através da escola e de outros meios formativos, contribua para a igualdade de oportunidades, a superação das desigualdades económicas, sociais e culturais, o desenvolvimento da personalidade e do espírito de tolerância, de compreensão mútua, de solidariedade e de responsabilidade, para o progresso social e para a participação democrática na vida colectiva» (sin traducción, http://www.wipo.int/wipolex/es/text.jsp?file_id=179473).

${ }_{23}$ «Los Estados partes en el presente Protocolo convienen en que la educación deberá orientarse hacia el pleno desarrollo de la personalidad humana y del sentido de su dignidad y deberá fortalecer el respeto por los derechos humanos, el pluralismo ideológico, las libertades fundamentales, la justicia y la paz.»

24 «Toda persona afectada por una disminución de sus capacidades físicas o mentales tiene derecho a recibir una atención especial con el fin de alcanzar el máximo desarrollo de su personalidad.» 
de la vocación artística y creativa de las personas de todas las edades, con prioridad para niñas, niños y adolescentes.» (art. 380).

Por su parte, la Constitución dominicana es un ejemplo emblemático de distribución de la prioridad del desarrollo humano entre varios campos de interés. En primer lugar, el artículo 43 titulado «Derecho al libre desarrollo de la personalidad» introduce la norma autónoma al respecto. Después, el artículo 55 expone el relevante papel de la familia diciendo que «La familia es el fundamento de la sociedad y el espacio básico para el desarrollo integral de las personas.» La Constitución protege el «desarrollo social, espiritual y físico» de los hijos (art. 55.9) y el «desarrollo armónico e integral» de las personas menores de edad (art. 56), destacando a continuación que «Los adolescentes son sujetos activos del proceso de desarrollo.» En el plano del derecho a la educación y a la cultura el artículo 63 confirma que «La educación tiene por objeto la formación integral del ser humano a lo largo de toda su vida y debe orientarse hacia el desarrollo de su potencial creativo y de sus valores éticos. No cabe duda de que el apoyo al libre desarrollo personal se funda en el derecho a la cultura al que se refiere el artículo 64 señalando: «Toda persona tiene derecho a participar y actuar con libertad y sin censura en la vida cultural de la Nación, al pleno acceso y disfrute de los bienes y servicios culturales, de los avances científicos y de la producción artística y literaria. [...El Estado] Reconocerá el valor de la identidad cultural, individual y colectiva, su importancia para el desarrollo integral y sostenible ...». Además, destaca la exposición que hace el artículo 217 vinculando el régimen económico del país con el desarrollo individual: «El régimen económico se orienta hacia la búsqueda del desarrollo humano.»

La persona humana es el centro de interés de los derechos fundamentales (humanos), así que la protección de la cualidad más inherente a este estatus, incluso determinante, y a la vez más dinámica y receptiva, es decir, la protección de la personalidad en el sentido psicológico del ser humano (la identidad ${ }^{25}$ ) debería ser reconocida y apoyada inequívocamente por cualquier ordenamiento jurídico.

Resumiendo, los contextos legislativos citados ejemplarmente $\mathrm{u}$ otros por tomar en consideración, numerosos y multifacéticos, solo permiten aproximarse a grandes rasgos al entendimiento jurídico de la noción misma del desarrollo de la personalidad, puesto que ni la

25 «la identidad de una persona comprende dimensiones biológicas, psicológicas, sociales, culturales y espirituales» como lo reconoce el Preámbulo a la Declaración universal sobre Bioética y Derechos Humanos del 19 de octubre de 2005. 
definen ni la desglosan, aunque sí la ponen en relación con otras figuras jurídicas y la propia acepción lingüística del término aporta mucho a la comprensión de la misma vinculándola con los conocimientos corrientes y científicos. Llegado este punto, debemos adentrarnos más el contenido jurídico del concepto del libre e íntegro desarrollo de la personalidad.

\section{EL ENTORNO JURÍDICO ALEMÁN}

La larga historia de reflexiones jurisprudenciales e interpretaciones judiciales, sobre todo desde el Tribunal Constitucional Federal alemán (TCFA), en búsqueda del contenido y alcance del derecho al libre desarrollo de la personalidad establecido por el artículo 2.1 GG demuestra que el término mismo - die freie Entfaltung der Persönlichkeit- el libre desenvolvimiento (el libre desarrollo) de la personalidad $^{26}$ no se entiende ni de forma clara ni inequívoca. Mientras que principalmente no haya ni razones semánticas ni doctrinales para una interpretación limitada del concepto de libre desarrollo de la personalidad, los comentarios doctrinales, la mayoría de los asuntos judiciales y las sentencias del TCFA se centran en solo un aspecto de éste, a saber, asignan al término en cuestión el atributo más próximo a las manifestaciones (expresiones, acciones, comportamientos) externas de la personalidad de uno, restringiendo el alcance de la noción a la llamada libertad general de actuaciones (acciones) de la persona (allgemeine Handlungsfreiheit). Así lo resume Epping ${ }^{27}$ :

El artículo 2 párrafo 1 GG por lo tanto protege la libertad de hacer y no hacer (dejar hacer, abstenerse) lo que se quiera. El término «la libertad general de acción» abarca esta libertad completa sin plena

${ }^{26}$ La palabra alemana die Entfaltung se acerca más a la española el desenvolvimiento y el desarrollo parece similar a la alemana die Entwicklung. El término «el libre desenvolvimiento de la personalidad» fuera del contexto alemán lo usan, entre otros, Alegre Martínez, M.Á. y Mago Bendahán, Ó. (2006). «Reconocimiento constitucional de la dignidad, individualidad y derechos de la personalidad». Revista de Derecho Político (UNED), núm. 66, p. 187 (http://revistas.uned.es/index.php/ derechopolitico/article/view/8989).

27 Epping, V. (2010). Grundrechte. Berlin Heidelberg: Springer-Verlag, p. 242. Traducción propia: «Art. 2 Abs. 1 GG schützt daher die Freiheit, zu tun und zu lassen, was man will. Der Begriff der "allgemeinen Handlungsfreiheit" erfasst diese umfassende Freiheit nicht ganz präzise; zutreffend wird daher auch von einer "allgemeinen Verhaltensfreiheit" gesprochen.» Del modo semejante lo comenta Wienbracke, M. (2013). Einführung in die Grundrechte, Wiesbaden, FOM-Edition, Springer Fachmedien, p. 255 (en el capítulo «Allgemeine Handlungsfreiheit, Art. 2 Abs. 1 GG»). 
precisión, justo se puede hablar también de una «libertad general de comportamiento».

A esta comprensión limitada a las expresiones (conductas) externas del sujeto se suma la formulación de la disposición misma del artículo 2.1 GG que alega que dicho derecho no vulnere ni los derechos del otro, ni el orden constitucional, ni la ley moral. Eso sugiere que el concepto del libre desenvolvimiento de la personalidad se refiere sobre todo a los comportamientos, declaraciones o acciones claramente manifestadas hacia afuera, puesto que los pensamientos y otros procesos psíquicos sin revelarse de alguna forma en el exterior no pueden infringir por sí mismos ni las leyes ni los derechos ${ }^{28}$, aunque sí pueden violar la ley moral, pero en este caso las repercusiones principalmente se encuentran fuera del foco del derecho positivo. A partir de tal interpretación, enfocada en la libertad general de acción, se han buscado los límites de su alcance desde la perspectiva de la coexistencia social o las preferencias o prioridades para la protección de los bienes y valores superiores ${ }^{29}$. El TCFA en su trabajo interpretativo en torno al artículo 2.1 GG concretizó algunos aspectos de dicha norma ${ }^{30}$.

Así, destaca la Sentencia BVerfGE 6, 32 [Wilhelm Elfes] ${ }^{31}$ que, a tenor del artículo 2.1 GG, el objeto del amparo es la libertad de acción en el sentido más amplio («die menschliche Handlungsfreiheit in weitestem Sinne»). En el asunto concreto se trataba de la libertad de viajar y la repercusión de ésta en el derecho a obtener el pasaporte ${ }^{32}$. De la sentencia citada emerge la dominante corriente jurisprudencial que centra la comprensión del derecho al libre desenvolvimiento de la personalidad regulado en el artículo 2.1 GG en el aspecto de la libertad general de acción ${ }^{33}$, luego de hecho lo limita. Sin embargo, el mismo Tribunal acude a la característica más íntima del ser humano

28 Peters, H. (1963). Das Recht auf freie Entfaltung der Persönlichkeit in der höchstrichterlichen Rechtsprechung. Arbeitsgemeinschaft für Forschung des Landes Nordrhein-Westfalen Geisteswissenschaften, Heft 109, Wiesbaden Springer Fachmedien, p. 16.

${ }^{29}$ Wintrich, J.M. (1957). „Zur Problematik der Grundrechte«, en Stein, E. Derecho Político (Lehrbuch des Staatsrechts). (1973). Traducción de Sainz Moreno. Madrid: Aguilar, pp. 20 y siguientes.

30 A continuación, se citarán los fragmentos de sentencias recogidas en Schwabe, J. (2009). Jurisprudencia del Tribunal Constitucional Federal Alemán. Extractos de las sentencias más relevantes compiladas por Jürgen Schwabe.KonradAdenauer-Stiftung, pp. 56 y siguientes (http://www.kas.de/wf/doc/kas_16817-544-430.pdf).

31 Entre corchetes se encuentran las denominaciones habituales de los casos citados en la nomenclatura de Schwabe, ibidem.

32 Schwabe, ibidem, p. 56.

33 Peters, op. cit., pp. 15-21. 
subrayando que él no puede desarrollar su naturaleza (Wesensanlage) como persona espiritual-moral (geistlich-sittlich) sin la libertad de acción (Handlungsfreiheit). De esta manera, el Tribunal marca la cualidad interna del ser humano: desarrollar su naturaleza como persona espiritual-moral, cuya protección es el objeto de preocupación del artículo 2.1 GG, como el referente (criterio) original para después derivar de este componente intrínseco del hombre tales derechos exactos que garanticen el desarrollo de éste. Es decir, el desarrollo de la persona como un ente espiritual y moral es el punto de partida y la libertad de comportamiento y actuación del ser humano más amplia posible es el condicionante primordial, pues no necesariamente el único, para conseguir dicho libre e íntegro desarrollo (interno) de la persona. De este modo, el Tribunal no se alejó de la comprensión del artículo 2.1 GG. que sirve de protección del desarrollo libre de una determinada cualidad interna del ser humano: su personalidad que no sea viable sin que la persona goce realmente de la libertad de actuar. Aparte del valor autónomo de proteger esta cualidad interna, el expresarse libremente hacia afuera (entre otros, emprender acciones concretas) es simplemente imprescindible para influir en la esfera espiritual y moral del hombre y asegurar en consecuencia «el desarrollo dentro del contenido-núcleo de la personalidad» («die Entfaltung innerhalb jenes Kernbereich des Persönlichkeit») ${ }^{34}$.

El concepto mismo del núcleo interno o ego, o yo, constituye un eje en torno del cual giran las consideraciones de Abraham Maslow ${ }^{35}$ acerca de la naturaleza psíquica y el desarrollo de la personalidad del ser humano en el contexto de conseguir la autorrealización. Entonces, la fuente de la libertad de manifestaciones externas está ligada estrechamente a la esfera interna (psíquica: espiritual, intelectual, emocional, sentimental) del individuo cuya protección está en primera línea amparada por la norma constitucional alemana ci$\operatorname{tada}^{36}$. Esta corriente interpretativa, centrada en la protección de ele-

34 Peters, op. cit., p. 16.

35 Maslow, A.H. (1982). El hombre autorealizado. Barcelona: Kairós, pp. 253, 256, 261, por ejemplo.

${ }^{36}$ De manera similar, lo consideran los tribunales norteamericanos a tenor de la protección de la dignidad humana, así «the Court equates dignity with the respect owed to the core characteristics of an individual's personality and the right to be free from government interference with the expression of those characteristics.» (Glensy, R.D. (2011). "The right to dignity». Columbia Human Rights Law Review, Volume 43 p. 90 (http://hrlr.law.columbia.edu/archives/volume-43/, acceso el 04.08.2017). Se puede ver que la característica clave de la personalidad humana y sus expresiones, aunque estrechamente ligadas, constituyen los bienes jurídicos protegidos separadamente y el derecho a la libertad de manifestaciones no agota el alcance y el contenido del derecho al respeto a la personalidad humana.

(C) UNED. Revista de Derecho UNED, núm. 23, 2018 
mentos especialmente importantes del desarrollo de la personalidad, con ello la protección de su contenido-núcleo («die Schutzes auf besonders wichtige Elemente der Persönlichkeitsentfaltung, mithin auf einen Kernbereich») se denomina la teoría del contenido-núcleo de la personalidad (die Persönlichkeitskerntheorie) ${ }^{37}$ y desafortunadamente está en cierta medida abandonada por la doctrina y la jurisprudencia. Este relativo abandono tuvo su causa en la percepción de que al referirse a la protección de la esfera interna (íntima) suponía un límite en relación con el artículo 2.1 GG («engere Deutungen des Art. 2 Abs. 1 GG») y, por consiguiente, reducía el alcance de su aplicación ${ }^{38}$. No obstante, ambos aspectos o líneas interpretativas no se contradicen, incluso coinciden, puesto que la protección de la esfera interna abarca, en mi opinión, plenamente el requisito de la libertad de acción.

La perspectiva de la libertad de acción atribuida al derecho al libre desenvolvimiento de la personalidad consiste en que se asegure que nadie, incluidos los poderes públicos, sin perjuicio de los límites legalmente establecidos, no puedan negar la libertad del sujeto, es decir, los terceros han de desistir de intervenir, cuestionar o prohibir ciertas manifestaciones y han de tolerar ciertos comportamientos del sujeto. Por lo contrario, la protección del desarrollo del contenido-núcleo de la personalidad no tiene tal limitación y de esta manera incluye hasta la obligación, destinada entre otros a las autoridades y los legisladores, de acometer determinadas acciones que contribuyan al desarrollo del individuo, luego el sujeto goza de medidas de reclamar ciertas prestaciones y comportamientos del Estado, por ejemplo, una educación adecuada.

Desde la perspectiva filosófica, la persona dispone de autonomía como sujeto moral kantiano, es el sujeto en su integridad y «las obras de las personas no agotan su personalidad» ${ }^{39}$. De esta manera el libre desarrollo de la personalidad no se puede reducir a la protección de las manifestaciones de ésta, ya que queda algo que va más allá de las expresiones observables (empíricas), es lo interno —el contenido-núcleo de la personalidad-que exige tanto la protección contra las influencias dañinas o bloqueadoras como la incentivación positiva. No basta amparar algún estado de la personalidad (mental, intelectual, espiritual, emocional), ya que este tipo de estado psíquico inmovilizado simplemente no existe; no se puede eludir estar

37 Epping, op. cit., pp. 237-238.

38 Epping, op. cit., p. 237.

39 González Amuchastegui, J. (2004). Autonomía, dignidad y ciudadanía. Valencia: Tirant Lo Blanch, pp. 426-427. 
en una interacción continua consigo mismo y con el ámbito externo. La protección del contenido-núcleo de la personalidad reside sobre todo en proteger el desarrollo de la libertad. Hay que fomentar el entorno oportuno para que las capacidades humanas se desarrollen, para lo cual se requiere una acción positiva (afirmativa) externa, por ejemplo, desde el plano legislativo y las políticas públicas ${ }^{40}$.

En síntesis, la libertad general de acción (allgemeine Handlungfreiheit), de externalizaciones y expresiones observables de la persona, es solo una de las varias realizaciones potenciales del derecho al libre desarrollo de la personalidad, aunque en el transcurso del tiempo se ha estado convirtiendo en la predominante referencia de la interpretación jurídica, cuyas encarnaciones se confirman en las sentencias citadas a continuación. Así, la Sentencia BVerfGE 34, 238 [Reproducción de una grabación secreta] aplica la norma del Artículo 2.1 GG a la protección de «la propia imagen, como el derecho de expresarse. Por consiguiente, toda persona puede - en principiodeterminar en forma autónoma e independiente quién puede grabar su voz, así como determinar si -y ante quién - puede ésta ser reproducida nuevamente» ${ }^{41}$. La Sentencia BVerfGE 99, 185 [Cienciología] deriva del Artículo 2.1 GG la protección de la imagen de la persona en la sociedad (la buena fama/la honra). De este modo la disposición "protege también al individuo de ser señalado erróneamente como miembro de una asociación o grupo, cuando dicha adscripción sea relevante para la personalidad y su imagen pública ${ }^{42}$. La Sentencia BVerfGE 96, 56 [Investigación de la paternidad] reflexiona acerca del «derecho del niño a conocer su origen, protegido en el art. 2, párrafo 1 en relación con el art. 1, párrafo 1 de la Ley Fundamental.» ${ }^{43}$. La Sentencia BVerfGE 101, 361 [Carolina de Mónaco] atañe a la protección de la esfera (vida) privada y resuelve que «La esfera privada, protegida por el derecho de la personalidad consagrado en el artículo 2, párrafo 1 en relación con el artículo 1, párrafo 1 de la Ley Fundamental, no se limita al ámbito doméstico. El individuo debe tener la posibilidad de moverse libremente en otros lugares - distinguidos de manera clara y separados-, sin ser mo-

${ }^{40}$ Igualmente, desde la perspectiva de la dignidad humana, la posición de que el Estado debe apoyar el autodesarrollo se confirma también en el ámbito jurídico norteamericano, así el Juez William Brennan en el asunto Furman v. Georgia, 1972, en Kateb, G. (2011). Human Dignity. The Belknap Press of Harvard University Press, p.15.

${ }^{41}$ Schwabe, op. cit., p. 59.

42 Schwabe, op. cit., p. 61.

${ }^{43}$ Schwabe, op. cit., p. 68. 
lestado con fotografías de carácter periodístico.» ${ }^{44}{ }^{45}$. La Sentencia BVerfGE 106, 28 [Grabación de conversaciones telefónicas] afirma que «La garantía del derecho a la protección de la palabra hablada forma parte del derecho general de la personalidad, previsto en el Artículo 2, párrafo 1 en relación con el Artículo 1, párrafo 1 de la Ley Fundamental; este derecho protege a los involucrados en una conversación e impide que una de las partes, por ejemplo mediante el uso de un micrófono, ponga el contenido de la conversación a disposición de un tercero no involucrado en la misma ${ }^{46}$. La Sentencia BVerfGE 65, 1 [Censo de Población] se refiere a la autodeterminación informativa y dispone que "Dentro de las condiciones para el moderno procesamiento de datos se encuentra el derecho general de la personalidad, contemplado en el artículo 2, párrafo 1, en relación con el artículo 1, párrafo 1 de la Ley Fundamental, y que protege a los individuos frente a la recolección, archivo, empleo y difusión ilimitada de sus datos personales. El derecho fundamental garantiza en esta medida la capacidad de los individuos, para determinar, en principio, la divulgación y empleo de sus datos personales.» ${ }^{47}$. Podemos añadir, además, que, en opinión del TCFA «no existe un «derecho a drogarse»» que se pueda deducir del Artículo 2.1 GG (BVerfGE 90, 145 [Cannabis] $]^{48}$ ).

El conjunto de sentencias citadas confirma que al bien protegido de libertad general de acción se pueden añadir otras esferas de amparo, tales como el derecho a la autodeterminación (Recht auf Selbstbestimmung); se trata de conocer el origen o el apellido de sí mismo, de controlar la difusión de datos personales o la autodescripción (Recht auf Selbstdarstellung), que entre otros tiene que ver con la imagen pública. Tal oportunidad de la extensa interpretación de preceptos relativos al derecho al libre desarrollo personal y también a la protección de la dignidad humana es la consecuencia del catálogo abierto de derechos subjetivos, incluidos fundamentales, que derivan de estos preceptos. Sin embargo, la mayoría de las referencias mencionadas en el artículo 2.1 GG, que además coinciden con la protección de la dignidad humana (Schutz der Menschenwürde) establecida por el artículo $1.1 \mathrm{GG}$, se alejan del concepto de

${ }^{44}$ Schwabe, op. cit., p. 72.

45 En cuanto a la protección contra la persecución periodística y la publicación de las fotografías, anteriormente nos referiremos al asunto von Hannover c. Alemania sentenciado por el TEDH el día de 24 de junio de 2004.

46 Schwabe, op. cit., p. 85.

47 Schwabe, op . cit., p. 94.

48 Schwabe, op. cit., p. 104. 
la libre y plena composición de la personalidad en el sentido de la formación del contenido-núcleo de la personalidad.

Como se ha acentuado anteriormente, el derecho al libre desarrollo de la personalidad está en la estrecha relación con el artículo 1.1 GG que proclama la protección de la dignidad humana, así siguiendo al Wintrich ${ }^{49}$ :

El cuidar y el proteger la libre autodeterminación de las personas y en consecuencia el desenvolvimiento de las habilidades y las fuerzas que residen en ella es la preocupación central del artículo 1 párrafo 1 de la Ley Fundamental.

La protección de tal atributo del ser humano como la dignidad implica que de ninguna manera la persona está a disposición del Estado o de la sociedad ${ }^{50}$, luego la ratificación de la dignidad humana hace rechazar «una visión totalizadora de la vida social, en el sentido de que no se conciben en él organismos colectivos con fines o vida superiores a los de los individuos que los componen ${ }^{51}$. De esta manera la persona no puede ser tratada por la ley o por el Estado como un mero objeto ${ }^{52}$, sino como un sujeto (Subjektprinzip ${ }^{53}$ ) de la ley y las actuaciones de los poderes públicos. Esta conclusión se extiende a todas las relaciones sociales. El principio de subjetividad del ser humano resulta en el hecho de que su personalidad instituye una esfera de interés y protección especiales como un parámetro constituyente del mismo, así como lo explica el TCFA:

En la democracia liberar la dignidad humana es el valor supremo. Ella es intocable y está para ser respetada y protegida por parte del Estado. Entonces, el hombre es una 'personalidad' dotada

${ }^{49}$ Wintrich, op. cit. p. 20 (traducción propia: «Die freie Selbstlbestimmung des Menschen und damit die Entfaltung der in ihm angelegten Fähigkeiten und Kräfte zu achten und zu schützen ist das zentrale Anliegen des Art. 1 Abs. 1 GG»).

50 Gómez Sánchez, op. cit., 2005: p. 221 y 2011: p. 41. Véase: Paredes Montiel, M. (2008). «La sentencia BverfG 115, 1181 BvR 357/05 del 15 de febrero de 2006 del Tribunal Constitucional Federal alemán, que declara inconstitucional el Artículo 14 de la Ley de Aviación Civil. Un precedente sobre el respeto a la vida y la dignidad humana.» Cuestiones Constitucionales. Revista Mexicana de Derecho Constitucional, Núm. 19, pp. 371-372(http://dx.doi.org/10.22201/iij.24484881e.2008.19, acceso el 21.07.2017).

${ }^{51}$ Mora, J.E. (2000). «La dignidad de la persona humana en la jurisprudencia constitucional española». Cuadernos de Bioética. Revista cuatrimestral de investigación 2. ${ }^{a}$, núm. 42. p. 259 (http://aebioetica.org/cuadernos-de-bioetica/archivohistorico/ano-2000/numero-42.html).

52 Viteri Custodio, op. cit., p. 120.

53 Zakariás, K. y Beneke, K. (2012). "Human dignity in the case-law of the Constitutional Courts of Germany, Hungary and Romania». Buletinul Curtii Constituţionale (The Constitutional Court Bulletin, Romania), núm. 2, pp. 46 y siguientes (https://www.ccr.ro/uploads/zakarias_benke_1.pdf). 
de la capacidad de diseñar su vida por responsabilidad propia. Su conducta y su pensamiento no pueden únicamente ser determinados por su ubicación social. Él es considerado más bien como capaz, y por consiguiente necesita conciliar (acordar) sus intereses e ideas con los demás. Por su dignidad se debe asegurarle [al ser humano] el desarrollo de su personalidad más amplio posible. Para el campo social y político esto significa que no es suficiente que la autoridad se esfuerce por ofrecer lo bueno para el bienestar de los "súbditos», más bien el individuo debe participar (responsabilizarse) en el grado más extenso posible en las decisiones relativas a la comunidad (el colectivo). El Estado tiene que abrirle el camino; esto se hace principalmente por el hecho de que la lucha por valores espirituales y la disputa (el análisis) de ideas son libres, en otras palabras, que la libertad de pensamiento está garantizada. La libertad de la mente es crucial para el sistema de la democracia liberal, es casi un prerrequisito para el funcionamiento de este orden [de la democracia liberal]; la libertad de la mente protege contra la petrificación y muestra la multitud de posibilidades de solución de problemas. ${ }^{54}$

Estas reflexiones acogen todos los hilos clave para entender las relaciones intrínsecas e irreducibles entre la dignidad humana, el libre desarrollo de la mente de la persona y la libertad del pensamiento en un sistema político basado en la democracia liberal. Así, la libertad del desarrollo espiritual y mental del individuo en el grado más amplio posible da la garantía para el desarrollo de la colectividad ${ }^{55}$. La confrontación y comparación de las propias ideas del

${ }^{54}$ Traducción propia. „In der freiheitlichen Demokratie ist die Würde des Menschen der oberste Wert. Sie ist unantastbar, vom Staate zu achten und zu schützen. Der Mensch ist danach eine mit der Fähigkeit zu eigenverantwortlicher Lebensgestaltung begabte „Persönlichkeit«. [...] (BVerfGE 5, 85; 1 BvB 2/51 [KPD-Verbot / Prohibición del Partido Comunista Alemán]).

${ }^{55}$ En cuanto a la cuestión del desarrollo humano la psicología «establece una triple distinción entre lo cognitivo, lo afectivo y lo social». La íntima relación entre lo «interno» de la persona (cognitivo, afectivo) y lo expuesto hacia afuera lo social reside en el hecho de que «el descubrimiento del otro como la posibilidad de establecer una relación con él están ligados a los progresos cognitivos y afectivos que dan cuenta también de la riqueza y de la complejidad creciente de las relaciones interpersonales». Sin embargo, se postula ciertos objetivos ante el proceso de desarrollo humano, digamos correcto, adecuado o esperado, tales son «las tres demandas generales que todas las sociedades efectúan sobre sus miembros: a. la capacidad de funcionar de modo competente y autónomo como individuo o adecuación individual; b. la capacidad de interactuar adecuadamente con los otros o adecuación interpersonal; y c. la capacidad para asegurar la cohesión social o adecuación social. Se sostiene, por tanto, que los individuos socializados y desarrollados deben ser autosuficientes en algún grado y ser responsables de su propia supervivencia, deben ser capaces de relacionarse con los otros de manera estable y predecible, y capaces de identificar las amenazas que atenten en contra de la integridad del grupo o la cohesión social y de implicarse en el establecimiento activo de la solidaridad social», en: Goñi Palacios, E. y Fernández Zabala, A. (2007). «Los dominios social y per- 
individuo con los demás tiene sentido solo si las mismas se crean, elaboran y forjan libremente en la mente de la persona, para lograrlo es imprescindible un marco externo (socio-jurídico) propicio. Es el principio de la dignidad humana que determina la situación (la posición) jurídica del contenido-núcleo de la personalidad (la esfera interna) protegido por el derecho al libre desenvolvimiento de la personalidad establecido por el artículo 2.1 GG y a la vez asegura la conformidad con éste y con los requisitos que lo subyacen ${ }^{56}$. Sin embargo, no basta que se rechacen las limitaciones al libre desarrollo del contenido-núcleo de la personalidad (la prohibición de injerencias restrictivas), sino que es necesario que se establezca un ámbito oportuno para su crecimiento y enriquecimiento (las actuaciones positivas por parte del Estado). Además, la identidad de la persona no se reduce a saber tales atributos personales como son su origen biológico (conocer al padre) o identificarse por el nombre y apellido propios ${ }^{57}$, es decir, a saber, quién soy y cómo me distingo "por fuera» de otras personas ${ }^{58}$, que se pueden llamar los condicionantes de identificación externa y objetiva. La personalidad única y la autonomía individual de cada sujeto incluye la percepción propia de ser un individuo particular y singular; el autorreconocimiento y el autorrespeto ${ }^{59}$, de la autocomprensión del sujeto, su singularidad moral, su capacidad de emitir juicios morales y elegir libremente, su aptitud para la búsqueda del bien, la virtud y la felicidad, su capacidad para construir conceptos generales y razonar, para reproducir, comunicar y provocar sentimientos. Todas estas características son imprescindibles para el libre desarrollo de los planes de vida y, a la vez, materializan la dignidad de la persona, no son alcanzables sin el libre desarrollo del sujeto. Todas las capacidades anteriores son

sonal del autoconcepto». Revista de Psicodidáctica 12(2), pp. 180 y 181 respectivamente (https://addi.ehu.es/handle/10810/7098).

56 Zakariás y Beneke, op. cit., p. 50.

57 BVerfGE 79, 256; BVerfGE 59, 216 y BVerfGE 104, 373. «[...] el «ser humano es inevitablemente cultural. Un ser cultural inmerso en un entorno natural». [se citan a B. Herreros Ruiz Valdepeñas y S. Delgado Bueno] La Declaración Universal sobre Bioética y Derechos Humanos proclama que "la identidad de una persona comprende dimensiones biológicas, psicológicas, sociales, culturales y espirituales"», en: Gómez Sánchez, Y. (2009). "Cooperación internacional y Bioética», en Brena Sesma, I. y Teboul, G. Hacia un instrumento regional interamericano sobre la Bioética. Experiencia y Expectativas, México, Instituto de Investigaciones Jurídicas, p. 359.

58 Zakariás y Beneke, op. cit., p. 52.

${ }^{59}$ Habermas, J. (2010). «El concepto de dignidad humana y la utopía realista de los derechos humanos». Diánoia, vol. LV, núm. 64, p. 17 (http://www.scielo. org.mx/scielo.php?script=sci_arttext\&pid=S0185-24502010000100001\&lng=es\& nrm=iso). 
propias y exclusivas de los seres humanos ${ }^{60}$ y confirman la dignidad de la persona. Por otra parte, son rasgos dinámicos y facultades que necesitan desarrollarse. Entonces, para la protección de la dignidad humana es vital garantizar el entorno apropiado para que estos atributos florezcan. Siguiendo a Kant, la dignidad del ser humano radica en «su autonomía o capacidad de darse leyes y afirma que exige tratar al hombre siempre como fin, nunca como medio» ${ }^{61}$. Esa autonomía del hombre se vincula en Bobbio con la libertad, como la que consiste en «el poder de darse normas a sí mismo y de no obedecer más normas que las que se da uno mismo. Como tal, se contrapone a constricción. Por ello se llama «libre» al hombre inconformista, que razona con sus propias ideas $[\ldots]_{»^{62}}$. Esta comprensión del concepto de libertad se relaciona con la voluntad de la persona, así «una voluntad libre es una voluntad que se autodetermina». La otra faceta de la libertad el filósofo percibe como contrapuesta a impedimento, es la que limita el poder del Estado, así en este sentido el término libertad "se compadece bien con "acción». Efectivamente, una acción libre es una acción lícita, que puedo hacer o no en cuando que no impedida». De esta manera el filósofo indica las dos esferas relevantes al libre desarrollo de la personalidad. Es decir, por un lado, el tener las propias ideas requiere que ellas se funden dentro del foro interno del individuo en condiciones de libertad y por otro la personalidad se realiza también en libres actuaciones y acciones del sujeto.

Al fin y al cabo, es la dignidad humana la que sienta las bases para establecer un «sistema de valores, que encuentra su centro en la personalidad humana, que se está desarrollando de manera libre dentro de la comunidad social» (BVerfGE 7, 19863).

Por consiguiente, en el marco constitucional alemán, el derecho a la libre composición de la personalidad, como una esfera íntima,

${ }^{60}$ Ansuátegui Roig, F.J. (2011). "Derechos fundamentales y dignidad humana». IDHBC (HURI-AGE). Papeles el tiempo de los derechos, núm. 10, pp. 10-11 (http:// hdl.handle.net/10016/19333).

${ }_{61}$ Pereira-Menaut, A-C. y Pereira Sáez, C. (2014). «De nuevo sobre la dignidad humana». Cuadernos de Bioética, vol. XXV, núm. 84, 2014/2. , p. 235 (http:// aebioetica.org/cuadernos-de-bioetica/archivo-on-line/2014/n\%C2\%BA-84-mayoagosto.html).

${ }^{62}$ Bobbio, N. (2003). Teoría General de la Política. Madrid: Trotta, p. 304. A continuación del párrafo las citas y reflexiones del filósofo provienen de la misma página del libro.

63 Traducción propia: „Dieses Wertsystem, das seinen Mittelpunkt in der innerhalb der sozialen Gemeinschaft sich frei entfaltenden menschlichen Persönlichkeit und ihrer Würde findet, muß als verfassungsrechtliche Grundentscheidung für alle Bereiche des Rechts gelten «. 
que igualmente se puede formular como el derecho a la libre autodefinición/autodeterminación (die freie Selbstlbestimmung), aparte del Artículo 2.1 GG, se relaciona fuertemente con la protección de la dignidad humana (art. 1.1 GG).

Desde el panorama jurídico más amplio, la tendencia doctrinalinterpretativa acerca de la norma correspondiente al libre desarrollo de la personalidad tan sólidamente centrada en la libertad de acción sorprende porque, como ya se ha explicado, el concepto mismo del desarrollo de la personalidad ligado en varios ordenamientos jurídicos nacionales e internacionales al proceso formativo del menor de edad, asume el significado relativo a influir en la esfera psíquica del joven con el fin de moldear su interior y solamente rara vez tiene que ver con algún tipo de manifestaciones externas ${ }^{64}$, como la libertad de vestimenta u obligatoriedad de usar el uniforme escolar o el uso libre del móvil en la escuela, que sí son demostraciones externas de la personalidad del sujeto. Así, el Preámbulo a la Convención sobre los Derechos del Niño de 1989 en la versión española declara:

que el niño, para el pleno y armonioso desarrollo de su personalidad, debe crecer en el seno de la familia, en un ambiente de felicidad, amor y comprensión [y sucesivamente el artículo 29.1.a insiste en que] la educación del niño deberá estar encaminada a desarrollar la personalidad, las aptitudes y la capacidad mental y física del niño hasta el máximo de sus posibilidades.

y su versión homóloga alemana oficial Konvention über die Rechte des Kindes vom 20. November 1989) lo presenta así:

in der Erkenntnis, dass das Kind zur vollen und harmonischen Entfaltung seiner Persönlichkeit in einer Familie und umgeben von Glück, Liebe und Verständnis aufwachsen soll [y siguiendo el Artículo 29.1.a)] die Bildung des Kindes darauf gerichtet sein muss, die Persönlichkeit, die Begabung und die geistigen und körperlichen Fähigkeiten des Kindes voll zur Entfaltung zu bringen.

Por tanto, el término Entfaltung representa mucho más que alguna acción manifestada hacia afuera, ni siquiera en el marco jurídico alemán hay razones para restringir la interpretación destinada únicamente a la libertad de acción (Handlugsfreiheit) apartándose de la dimensión interna de la persona, es decir, de la libre composición (formación) de la personalidad del individuo.

${ }^{64}$ Véase: Leiva Ramírez, E., Torres Santamaría, M., Baquero Urrego, A., Gil Silva, J. (2010). «Violación del libre desarrollo de la personalidad por parte de las Instituciones educativas con relación a la longitud y corte del cabello». Nova et Vétera, vol. 19, núm. 63 (https://dialnet.unirioja.es/servlet/articulo?codigo=3732076).

(C) UNED. Revista de Derecho UNED, núm. 23, 2018 
Realmente, el derecho como tal rara vez se interesa por los estados psíquicos de la persona ${ }^{65}$, de ahí que se plantee la cuestión de por qué debe afectar al desarrollo de la personalidad en su dimensión interna (el contenido-núcleo). Aunque se trata de una característica más íntima del ser humano, pues es la que hace distinguir a las personas entre sí como la fuente (el origen) de sus conductas (demostraciones) observables desde afuera, incluidas las manifestaciones de las competencias sociales, intelectuales, artísticas y profesionales, que sí ya son el objeto de preocupación de la sociedad y del derecho, puesto que el funcionamiento de la sociedad depende plenamente de las cualidades y las capacidades mentales (psíquicas) de sus miembros. Aunque las correlaciones entre las intervenciones y circunstancias externas, como por ejemplo a través del proceso educativo, y las influencias sobre la personalidad no son sabidas a ciencia cierta, pero en general se puede figurar que la enseñanza, el aprendizaje o la acumulación de experiencias laborales y sociales influyen positivamente en esta esfera escondida del individuo en forma de adquisición de nuevas capacidades de creación, actuación y solución de problemas, cuyas expresiones externas (retroacciones) ya son claramente perceptibles por el entorno de la persona. Entonces, en el marco jurídico, al hablar de la protección del libre desarrollo de la personalidad del sujeto se debe tener en consideración el establecimiento del conjunto de actuaciones e incentivos de índole familiar, escolar o cultural y otras políticas públicas que influyen en la composición de la personalidad para conseguir su florecimiento y lograrla formación del ciudadano activo, autosuficiente y útil para la comunidad.

Así, pues, aunque la libre expresión hacia afuera y todas las interacciones del individuo con el entorno son imprescindibles para el libre desarrollo personal, ya que permiten confrontarse y provocan retroalimentación, por otro lado, son solo unos de muchos factores que estimulan la evolución de la personalidad humana que merezcan ser protegidos y apoyados.

\section{EL ENTORNO JURÍDICO ESPAÑOL. EL LIBRE DESARROLLO PERSONAL Y LA DIGNIDAD HUMANA}

En el ordenamiento constitucional español la dignidad de la persona y el libre desarrollo de la personalidad sientan fundamentos

${ }^{65}$ El derecho civil se interesa por la libertad, claridad e intencionalidad psíquicas a la hora de emprender los actos jurídicos voluntarios, en caso opuesto pueden adolecer de ciertos vicios y el derecho penal a la hora de evaluar el dolo o la culpa. 
del orden político y de la paz social, ambos valores mantienen un vínculo estrecho entre sí. Así, bajo el Título I De los derechos y deberes fundamentales, el artículo $10.1 \mathrm{CE}$ proclama lo siguiente:

La dignidad de la persona, los derechos inviolables que le son inherentes, el libre desarrollo de la personalidad, el respeto a la ley y a los derechos de los demás son fundamento del orden político y de la paz social.

Las disposiciones relativas a la dignidad humana y el libre desarrollo de la personalidad contenidos en el artículo 10.1 CE formalmente se encuentran fuera del conjunto de los derechos fundamentales establecidos en el Capítulo II, Sección 1. ${ }^{a}$ De los derechos fundamentales y de las libertades públicas ${ }^{66}$. Además, el artículo 53.1 $\mathrm{CE}$ establece que los poderes públicos quedan vinculados solamente a los derechos y las libertades reconocidos en el Capítulo II Derechos y libertades, excluyendo así el artículo 10.1 CE. Esta exclusión se ratifica adicionalmente por el artículo 53.2 CE que excluye igualmente el artículo $10 \mathrm{CE}$ del recursos de amparo ante el tribunal Constitucional ya que tal garantía es aplicable exclusivamente al artículo 14 y la Sección 1. ${ }^{\text {a }}$ del Capítulo II (Título I). Sin embargo, esta configuración no imposibilita mantener que «La dignidad de la persona, valor superior o principio general del Derecho, en cuanto se ha positivizado en la Constitución es norma de Derecho positivo. No quiere esto decir que haya perdido el carácter de principio. Sino que, además, es norma jurídica constitucional directamente obligatoria.» ${ }^{67}$. Dicho razonamiento analógicamente se puede aplicar al libre desarrollo de la personalidad por el mismo trato legislativo, la ubicación del artículo 10.1 CE.

${ }^{66}$ Alonso de Antonio menciona que el constituyente español a la hora de elaborar la Constitución Española del año 1978 se había inspirado en la normativa alemana en relación con la implementación de los preceptos correspondientes a la protección de la dignidad humana y el derecho al libre desarrollo de la personalidad. Alonso de Antonio, A.L. (2001). "Aproximación al marco constitucional de los derechos fundamentales». Anuario de derechos humanos, núm. 2, p. 38 (https://dialnet. unirioja.es/ejemplar/94401). Véase también: Alvarado Tapia, K. del Pilar (2015). «El libre desarrollo de la personalidad. Análisis comparativo de su reconocimiento constitucional en Alemania y España». Revista IUS (Revista de la Facultad de Derecho) de la Universidad Católica Santo Toribio de Mogrovejo, vol. 1, núm. 10 (http:// publicaciones.usat.edu.pe/index.php/ius/article/view/271). Véase también: Viteri Custodio, D.D. (2012). «La naturaleza jurídica de la dignidad humana: un análisis comparado de la jurisprudencia del Tribunal Constitucional español y el Tribunal Constitucional Federal alemán». Estudios de Derecho, vol. 69, núm. 153, p. 124 (https://aprendeenlinea.udea.edu.co/revistas/index.php/red/article/view/14143).

${ }^{67}$ González Pérez D.J. (1985). «La dignidad de la persona en la jurisprudencia constitucional». Anales, núm. 62, pp. 136-137 (http://www.racmyp.es/academicos/ numerarios. $\mathrm{cfm} ? \mathrm{ac}=1 \& \mathrm{id}=26 \& \mathrm{sc}=\mathrm{i})$. 
Sin embargo, en la Sentencia 64/1986 de 21 de mayo el TCE, al rechazar la norma del artículo $10.1 \mathrm{CE}$ como un fundamento autónomo de amparo, le atribuyó el carácter de criterio de interpretación de los derechos fundamentales y las libertades públicas. Aunque en el Auto 149/1999, de 14 de junio, el Tribunal sí toma en consideración «la existencia de un pretendido derecho fundamental a la dignidad humana que opere de forma autónoma e independiente ex art. $10 \mathrm{CE}$ », reitera a la vez que «la dignidad de la persona no se reconoce en nuestra Constitución como un derecho fundamental sino como «fundamento del orden político y la paz social»». Así, las formulaciones contenidas en el artículo 10.1 CE pueden reconocerse como los principios constitucionales ${ }^{68}$ o los principios axiológicos $^{69}$ y respectivamente sus referentes: la dignidad humana y el libre desarrollo de la personalidad como bienes jurídicos constitucionalmente protegidos ${ }^{70}$. No obstante, el alcance y la efectividad del artículo 10.1 CE se proyectan sobre situaciones y casos concretos como señala Gómez Sánchez refiriéndose a la Sentencia STC 214/1991, de 11 de noviembre del TCE: «La dignidad es [...] el «rango o categoría de la persona como tal», dignidad que «deben respetar tanto los poderes públicos como los ciudadanos, de acuerdo con lo dispuesto en los artículos 9 y 10 de la Constitución»» e inclinándose hacia la posición de que «El máximo nivel del reconocimiento de este carácter autónomo de la dignidad la configuraría como un «derecho a la dignidad» [...] Sí puede deducirse, en mi opinión, este concepto de dignidad como derecho autónomo del artículo 10.1 de la Constitución española.» ${ }^{71}$.

Si bien la posición formal de los preceptos relativos a la dignidad humana y el libre desarrollo de la personalidad, su carácter jurídico y el grado de vinculación juegan un papel clave para su utilización en resolución formal de asuntos, es imprescindible saber los elementos

68 Viteri Custodio, ibídem, p. 114.

${ }^{69}$ Oehling de los Reyes, A. (2011). «El concepto constitucional de dignidad de la persona forma de comprensión y modelos predominantes de recepción en la Europa continental». Revista española de derecho constitucional, año n. ${ }^{\circ}$ 31, núm. 91, p. 164 (https://dialnet.unirioja.es/servlet/articulo?codigo=3622297).

${ }^{70}$ Teresa Freixes citada en Pascual Lagunas, E. (2009). Configuración jurídica de la dignidad humana en la jurisprudencia del Tribunal Constitucional. Barcelona: Editorial J.M. Bosch, p. 21. La dignidad como «bien constitucional», como "principio», como «valor», como «derecho», como «norma» y como «límite» en García Cuadrado, A.M. (2012). "Problemas constitucionales de la dignidad de la persona». Persona y Derecho, vol. 67(2), pp. 476 y siguientes (https://www.unav.edu/ publicaciones/revistas/index.php/persona-y-derecho/issue/view/107).

${ }^{71}$ Gómez Sánchez, Y. (2005). "Dignidad y Ordenamiento Comunitario». Revista de derecho constitucional europeo, núm. 4, pp. 228 y 224 (https://dialnet.unirioja.es/ servlet/articulo?codigo $=1972258$ ). 
materiales del contenido jurídico (la acepción) de los conceptos mismos de la dignidad humana y el libre desarrollo de la personalidad, con independencia de su calificación como derechos fundamentales, directrices interpretativas, principios, valores o bienes jurídicos de otra vertiente, puesto que cada una de estas atribuciones cuenta con una determinada relevancia jurídica en dado ordenamiento.

De la dignidad humana surge el conjunto de los derechos fundamentales, así como también tales derechos subjetivos de la personalidad como el derecho a la autodeterminación física, el derecho a la autodeterminación psíquica, que incluye o coincide con el derecho al libre desarrollo de la personalidad, y el derecho a la autodeterminación informativa, incluido el derecho al olvido tan característico e importante en la era digital. La autodeterminación en estos contextos significa que la decisión acerca de qué quiere el sujeto que se haga con su cuerpo (sustrato corporal ${ }^{72}$ ), con su mente, con sus emociones y con la información sobre el mismo está exclusivamente en las manos del propio sujeto ${ }^{73}$. Entonces, «la dignidad es el rango o la categoría que corresponde al hombre como el ser dotado de inteligencia y libertad» y consiste «en que el hombre, como ente éticoespiritual, puede por su propia naturaleza, consciente y libremente, autodeterminarse, formarse y actuar sobre el mundo que le rodea ${ }^{74}$. La dignidad se asocia intrínsecamente con «la capacidad humana de autogobierno individual $»^{75}$, la autolegislación kantiana, la autodisponibilidad y la autodeterminación que corresponden a los campos vitales del ser humano, es decir, con decidir por su cuenta sobre su propia condición y su propio proyecto de vida.

Al destacar el concepto y la finalidad de la autorrealización de la persona a través de su vida y de sus acciones, Pelé ${ }^{76}$ relaciona la dignidad humana con el libre desarrollo de la persona de tal manera:

${ }^{72}$ Gómez Sánchez, Y. (2011). «Dignidad y autodeterminación física como fundamento del estatuto del paciente». Acta Bioethica, núm. 17 (1), p. 42 (http://dx.doi. org/10.4067/S1726-569X2011000100005).

${ }^{73}$ hasta si querer saber toda la información sobre sí mismo, al respecto, véase: Gómez Sánchez, Y. (2008). «La protección de los datos genéticos. El derecho a la autodeterminación informativa «. Derecho y salud, vol. 16, núm. Extraordinario 1 (https://dialnet.unirioja.es/ejemplar/186750).

${ }^{74}$ Viteri Custodio, op. cit., p. 120, cita respectivamente a González Pérez y von Wintrich, es decir González Pérez, J. (1986). La dignidad de la persona. Madrid: Civitas, p. 11 y Wintrich, op. cit. p. 236.

${ }^{75}$ González Amuchastegui, op. cit., p. 423.

76 Pelé, A. (2006). Filosofía e historia en el fundamento de la dignidad humana. Tesis doctoral en Universidad Carlos III de Madrid. Instituto de Derechos Humanos «Bartolomé de las Casas», pp. 180-181 (http://e-archivo.uc3m.es/ handle/10016/3052). 
Este libre desarrollo como se ha visto antes, deriva de una consideración previa del individuo como un ser capaz de proyectarse, lo que he encajado en la consideración del Hombre como un «ser en proyecto» y que implícitamente tendría sus raíces formales en el «crecimiento vegetal» en Platón. La dignidad humana se concreta hoy porque se reconoce al ser humano una libertad para plasmar sus distintas aspiraciones. Ahora bien, dicho planteamiento implica dos elementos iniciales: primero, que el ser humano pretenda «desarrollarse» (como "ser en proyecto») y, segundo, que busca un sentido a este desarrollo, lo que puede consistir en la felicidad. La dignidad humana encontró en la autonomía individual el medio para plasmar esas dos aspiraciones.

A la identificación del contenido sustancial del concepto de la dignidad humana se acerca el TCE en la Sentencia 53/1985, de 11 de abril:

la dignidad es un valor espiritual y moral inherente a la persona, que se manifiesta singularmente en la autodeterminación consciente y responsable de la propia vida y que lleva consigo la pretensión al respeto por parte de los demás.

Así, el TCE al aunar la característica descriptiva de la dignidad humana como un valor espiritual y moral inherente a la persona con la conclusión dispositiva que ella se manifiesta singularmente en la autodeterminación consciente y responsable de la propia vida y que lleva consigo la pretensión al respeto por parte de los demás abre al sujeto el campo para levantar determinadas reivindicaciones. La condición de que la persona dispone del derecho a la autodeterminación consciente y responsable de la propia vida que sale de su dignidad significa la autonomía de componer su identidad y personalidad, esbozar e implementar su propio proyecto de vida ${ }^{77}$ ejerciendo su libertad que se enraíza en su inteligencia y voluntad ${ }^{78}$. La libertad de la persona es una de las cualidades objetivamente observables. De la percepción, la conciencia y el reconocimiento jurídico de la autonomía interna de la persona surgen tanto la protección de esta autonomía como las limitaciones a las normativas que son impuestas a la persona misma por la ley o la sociedad. El sujeto percibe a sí mismo como libre y a la vez lo muestra hacia afuera. El abordar la tarea de componer (moldear) libremente e íntegramente la identidad por parte del individuo y, por consiguiente, emprender y seguir un proyecto de vida propio, independientemente elegido y trazado, requiere tanto un entorno socio-jurídico oportuno y tolerante, como

77 Véase: el capítulo Autodeterminación: El Proyecto de Vida en Pascual Lagunas, op. cit., pp. 83 y siguientes.

${ }^{78}$ Mora, op. cit., p. 259. 
la admisión del estatus autónomo por parte del propio individuo, e igualmente exige el respeto a este proyecto, a la persona misma y a su individualidad por parte de los demás integrantes de la sociedad. Recogiendo estos aspectos integrados en el concepto de la dignidad humana se ratifica que:

[la idea iusnaturalista del hombre] como ser éticamente libre [... se enlaza] con la doctrina kantiana, según la cual, la dignidad es la dimensión moral de la personalidad y se fundamenta en la libertad y autonomía del individuo ${ }^{79}$ [...y luego confirmando] el reconocimiento de la total autodisponibilidad, de cada ser humano, sin interferencias o impedimentos externos. [...así] el hombre posee la dignidad de persona como ser capaz de responsabilidad, por virtud de su libertad y capacidad de autodeterminación, y por esta razón, la libertad es el rasgo distintivo de su naturaleza. ${ }^{80}$ [En suma] la dignidad aparece [...] como una seña de identidad del ser humano, como ser dotado de inteligencia y libertad, como ser moral [...] la dignidad estriba en esa "versatilidad", libertad o capacidad humana de poder llegar a lo más alto, porque el hombre nace digno y todos los seres humanos son igualmente dignos. ${ }^{81}$

En síntesis, la autodeterminación del individuo en su sentido más amplio se refiere a la condición propiamente humana de la persona y está ligada estrechamente tanto a la esfera física como a la esfera interna del ser humano, es decir, a lo psíquico, intelectual, espiritual, axiológico, luego irreduciblemente atribuida al derecho al libre desarrollo de este ámbito y estas capacidades. Por lo tanto,

${ }^{79}$ Ibídem.

${ }^{80}$ Mora, op. cit., p. 259, cita a Messner, J. (1967). Ética social politica y económica a la luz del Derecho Natural (Das Naturrecht. Handbuch der Gesellschaftsethik, Staatsethik und Wirtschaftsethik). Ediciones Rialp, p.147.

${ }^{81}$ Marín Castán, M.L. (2007). «La dignidad humana, los Derechos Humanos y los Derechos Constitucionales.» Revista de Bioética y Derecho, núm. 9, p. 1 (http:// dx.doi.org/10.1344/rbd2007.9.7833). «Llegar a lo más alto» significa el «desarrollo máximo de las potencialidades humanas»(Pelé, op. cit, p. 350). Este concepto arranca en «el pensamiento socrático-platónico [que] implicó un ensimismamiento de la persona humana a través de un doble proceso reflexivo. Primero, concibió la conciencia de la individualidad humana a través de la identificación y del ejercicio de las facultades más nobles de la naturaleza humana. Segundo, orientó el ejercicio de esas facultades hacia el conocimiento del mundo y el desarrollo, el interés, el respecto y la protección del alma humana. El Hombre estaba dotado de nuevas cualidades y tenía que tener conciencia de sí mismo tanto para manifestar y defender esas cualidades como para conocer sus limitaciones. En este doble movimiento se encontraba su dignidad.» (Pelé, op. cit., p. 100). A continuación, «La naturaleza única de los Hombres se caracterizó por la racionalidad y la búsqueda de la felicidad. Dos rasgos que se conectaban entre sí y que describían al ser humano, a través del movimiento, cuyo fin implicaba el máximo desarrollo y uso de sus facultades cognitivas. Esos dos rasgos se conectaron con un tercero que abundó en la especificidad del ser humano, relativo a su forma de relacionarse con los otros individuos. El Hombre era un «animal político», rasgo fundamental de la dignidad de la naturaleza humana» (Pelé, op. cit., p. 123). 
se trata de la autodeterminación en relación con la personalidad. Siguiendo la explicación dada por Gómez Sánchez ${ }^{82}$ «el Tribunal Constitucional estimó que existe un derecho de autodeterminación, «...es decir, capacidad de autodeterminación consciente y responsable de la propia vida», lo cual "afecta el derecho al libre desarrollo de la personalidad», consagrado en el artículo 10.1 de la Constitución española.»En cuanto a la libertad de comportamiento el TCE confirmó en la Sentencia 98/1986 de 10 de julio que incluso en las circunstancias de detención que es «cualquier situación en que la persona se vea impedida u obstaculizada para autodeterminar» no se producen los efectos absolutos, que vayan más allá de lo necesario y apartan a la persona del amparo constitucional relativo, luego (fundamento jurídico $4 .^{\circ}$ de la Sentencia citada):

no es constitucionalmente tolerable que situaciones efectivas de privación de libertad —en las que, de cualquier modo, se impida u obstaculice la autodeterminación de la conducta lícita- queden sustraídas a la protección que a la libertad dispensa la Constitución por medio de una indebida restricción del ámbito de las categorías que en ella se emplean.

La relación intrínseca e irreducible entre la dignidad humana, la propia naturaleza del hombre y la autodeterminación del ser humano la consideró el TCE también en la Sentencia 120/1990, de 27 de junio (fundamento jurídico $4 .^{\circ}$ ),

la regla del art. 10.1 C.E. implica que, en cuanto «valor espiritual y moral inherente a la persona» (STC 53/1985, fundamento jurídico $8 .^{\circ}$ ), la dignidad ha de permanecer inalterada cualquiera que sea la situación en que la persona se encuentre - también, qué duda cabe, durante el cumplimiento de una pena privativa de libertad-.

Además, el TCE cita al Abogado del Estado (Antecedentes 9. ${ }^{\circ}$ ) que había confirmado que en el caso

del tratamiento médico coercitivo [...] un tratamiento de ese carácter que no pueda ser justificado jurídicamente merecería ser calificado de humillante y acaso envilecedor, por incompatible con la dignidad de la persona, ya que el paciente se reduciría a ser una cosa dotada de vida en manos de quien aplica el tratamiento.

Las conclusiones del TCE las resume Gómez Sánchez de este modo:

El reconocimiento de la dignidad humana obliga pues a tratar a todo ser humano de acuerdo con su propia naturaleza, ya que éste

82 Gómez Sánchez (2011), op. cit., p. 42. 
conserva su dignidad en toda situación y cualquiera que fuera la naturaleza de su comportamiento. ${ }^{83}$

En suma, cualquiera que sea la referencia meta-jurídica para captar la sustancia de la dignidad humana y su relevancia para el determinado ordenamiento jurídico, la acepción de ésta reconocida en el sistema legislativo está anclada sólidamente en la reflexión antropológica y la referencia a lo humano ya sea de índole religiosa o laica ${ }^{84}$. Al aproximarse a relacionar la esfera de percepción filosófica y lo jurídico se puede pronunciar que «el Derecho constitucional es únicamente una positivación de las posibilidades y funciones propias del mundo del espíritu y, por tanto, no se entiende sin aquéllas; y a la inversa, éstas no son realizadas de forma plena y permanente sin su positivación jurídica» ${ }^{85}$. Si bien el reconocimiento textual de la dignidad humana en el conglomerado constitucional puede transformar el valor o el postulado filosófico en algún tipo de norma jurídica ${ }^{86}$, la comprensión de la noción misma mantiene una relación estrecha con su origen extrajurídico ${ }^{87}$. En cuanto al marco de concretización jurídica, la positivación de la dignidad humana en el ordenamiento legislativo "exige prestaciones positivas del Estado y abstenciones de este mismo en la medida que no debe atentar contra ella» ${ }^{88}$. Las mismas conclusiones atañen al concepto del libre desarrollo de la personalidad.

\section{CONCLUSIONES}

Son varios los derechos y libertades declarados abiertamente o reconocidos implícitamente por los ordenamientos constitucionales y el derecho internacional que contribuyen al libre desarrollo de la personalidad del ser humano, entre ellos la protección de la libertad como tal (contra la detención ilegítima u otras medidas que impidan u obstaculicen la autodeterminación o el comportamiento de la persona), la libertad de expresión, pensamiento e investigación científica, la protección de la vida privada y familiar, el derecho a la edu-

83 Gómez Sánchez (2011), op. cit., p. 41.

${ }^{84}$ Oehling de los Reyes, op. cit., pp. 138-139, y Galán Juárez, M. (1999). Antropología y Derechos Humanos. Madrid: Editorial Dilex, pp. 75 y siguientes.

${ }_{85}$ citado por Oehling de los Reyes, op. cit., p. 136.

${ }^{86}$ Oehling de los Reyes, op. cit., p. 136.

87 Dentro de la doctrina alemana para Nipperdey y Badura respectivamente la dignidad parece influenciada por la realidad histórica y su carácter deriva «de la experiencia social e histórica» (citados por Oehling de los Reyes, op. cit., p. 148).

${ }^{88}$ Oehling de los Reyes, op. cit., p. 137, cita a Lucas Verdú, P. (1984). Estimativa y politica constitucionales. Universidad Complutense de Madrid, pp. 111 y 112.

(c) UNED. Revista de Derecho UNED, núm. 23, 2018 
cación y activa participación en la vida cultural. De hecho, podría afirmarse que la mayoría de los derechos humanos y fundamentales confluye en la consecución del desarrollo personal.

Reconocer el derecho fundamental al libre desarrollo de la personalidad del individuo y extender su alcance lo más posible se justifica tanto por el hecho de que es la persona en todas sus dimensiones el centro de interés y el sujeto de todos los derechos fundamentales, como porque este propósito consagra legislativamente el reconocimiento de un valor de gran envergadura social. Una interpretación rigurosa pero amplia del concepto jurídico libre e integro desarrollo de la persona, ratifica la relevancia de dicho concepto para la condición de la sociedad en su totalidad y a la vez exige la introducción de medidas concretas y adecuadas, ya sean de naturaleza legislativa o de soft law (las políticas públicas), como parte de cumplimiento de obligaciones positivas de implementación efectiva del derecho correspondiente.

El concepto del libre y pleno desarrollo de la personalidad del sujeto dispone de distintos atributos, uno de ellos reside en las garantías para efectuar la libertad de acción, es decir de manifestarse hacia afuera que además coincide con la libertad de la vida privada y social, es decir de comportarse libremente e iniciar y mantener relaciones con otras personas exentas de intromisiones, impedimentos y autocensura (la protección y el respeto a la vida privada), así se trata de expresiones de la personalidad en la esfera externa del individuo $\mathrm{y}$, por otro lado, consiste en poder desarrollar libremente y plenamente la esfera interna (personal, íntima) del mismo, la zona de lo psíquico, intelectual, cognitivo, axiológico, emocional, sentimental y espiritual de la persona.

Los instrumentos político-jurídicos que sirven para apoyar el libre desarrollo del ser humano coinciden estrechamente con la protección de la dignidad humana, fortaleciendo el contenido-núcleo de la personalidad (la esfera interna del ser humano) a fin de facilitar al sujeto llegar a lo más alto, no pueden reducirse a asegurar la mera libertad de comportamiento (acción, actuación) en el grado socialmente aceptable, sino han de encaminarse hacia el emprendimiento de determinadas acciones positivas del Estado, para que se ofrezcan unas prestaciones concretas de carácter de servicios dirigidos al ciudadano y accesibles a él. Se trata de implementar tales medidas públicas y soluciones legislativas, incluida financiación de determinadas actividades, para que se aseguren las oportunidades e infraestructuras que sirvan para la formación (educación) de la persona destinada a satisfacer las exigencias actuales vitales o labora- 
les mediante el acceso y la reutilización de ciertos recursos de conocimiento, tratándose de escuelas, plataformas y entidades de acceso a los contenidos de conocimiento, ciencia y cultura, bibliotecas, mediatecas, filmotecas, archivos, plataformas de las administraciones públicas e instituciones de investigación, u otros establecimientos físicos o virtuales, etc. ${ }^{89}$ Esta responsabilidad basada en la comprensión completa del concepto del libre desarrollo de la personalidad coincide con el efecto de irradiación de los derechos fundamentales en la totalidad del sistema jurídico ${ }^{90}$. La obligatoriedad de actuar positivamente por parte del poder público repercute también en el hecho de que se introduzcan o modifiquen las normas jurídicas (las leyes) del modo que garantice, confirme y refuerce el entorno jurídico propicio al desarrollo personal, incluido el delicado campo del derecho de autor y propiedad intelectual de relevancia esencial al respecto.

\section{BIBLIOGRAFÍA}

Alegre Martínez, M.Á. y Mago Bendahán, Ó. (2006). «Reconocimiento constitucional de la dignidad, individualidad y derechos de la personalidad».Revista de Derecho Político (UNED), núm. 66.

Alexy, R. (2012). Teoría de los Derechos Fundamentales. Madrid, Centro de Estudios Políticos y Constitucionales.

Alonso DE ANTONio, A.L. (2001). «Aproximación al marco constitucional de los derechos fundamentales». Anuario de derechos humanos, núm. 2.

Alvarado TAPIA, K.P. (2015). «El libre desarrollo de la personalidad. Análisis comparativo de su reconocimiento constitucional en Alemania y España». Revista IUS (Revista de la Facultad de Derecho) de la Universidad Católica Santo Toribio de Mogrovejo, Vol. 1, núm. 10.

Ansuátegui Roig, F.J. (2011). «Derechos fundamentales y dignidad humana».Papeles el tiempo de los derechos, núm. 10.

Atienza, M. (2003). El sentido del Derecho. Barcelona: Ariel.

${ }^{89}$ Buganza González, M.C. (2006). El derecho de autor y el derecho de acceso a la cultura (http://www.tdx.cat/bitstream/handle/10803/1406/MCBG_TESIS.pdf; jsessionid=93BBC17A306496BC5F6F48C1067F4034.tdx2 ?sequence $=1$ ). Tesis en la Universidad de Barcelona, p. 188.

${ }^{90}$ Alexy, R. (2012). Teoría de los Derechos Fundamentales. Madrid: Centro de Estudios Políticos y Constitucionales, p. 465. 
Bobbio, N. (2003). Teoría General de la Política. Madrid: Trotta.

Buganza González, M.C. (2006). El derecho de autor y el derecho de acceso a la cultura. Tesis en la Universidad de Barcelona.

Chiassoni, P. (2011). Técnicas de interpretación jurídica. Breviario para juristas. Madrid: Marcial Pons.

EPPING, V. (2010). Grundrechte. Berlin Heidelberg, Springer-Verlag.

Galán JuÁrez, M. (1999). Antropología y Derechos Humanos. Madrid, Editorial Dilex.

García CuAdrado, A.M. (2012). «Problemas constitucionales de la dignidad de la persona». Persona y Derecho, Vol. 67(2).

García MACHO, R. y Sommermann, K.P. (2003) Ley Fundamental alemana (traducción al español) accesible en la página de Deutscher Bundestag.

Glensy, R.D. (2011). «The right to dignity». Columbia Human Rights Law Review, Volume 43.

Gómez SÁNCHEZ, Y. (2005). «Dignidad y Ordenamiento Comunitario». Revista de derecho constitucional europeo, núm. 4.

Gómez SÁNchez, Y. (2008). «La protección de los datos genéticos. El derecho a la autodeterminación informativa «. Derecho y salud, Vol. 16, núm. Extraordinario 1.

Gómez SÁNchez, Y. (2009). "Cooperación internacional y Bioética», en Brena Sesma, I. y Teboul, G. Hacia un instrumento regional interamericano sobre la Bioética. Experiencia y Expectativas, México, Instituto de Investigaciones Jurídicas.

Gómez SÁNchez, Y. (2011). «Dignidad y autodeterminación física como fundamento del estatuto del paciente». Acta Bioethica, 17(1).

González Amuchastegui, J. (2004). Autonomía, dignidad y ciudadanía. Valencia: Tirant Lo Blanch.

González Pérez, D.J. (1985). «La dignidad de la persona en la jurisprudencia constitucional», Anales, núm. 62.

González Pérez, J. (1986). La dignidad de la persona. Madrid: Civitas.

GoÑ Palacios, E. y Fernández Zabala, A. (2007). «Los dominios social y personal del autoconcepto». Revista de Psicodidáctica 12(2).

Habermas, J. (2010). «El concepto de dignidad humana y la utopía realista de los derechos humanos». Diánoia. Volumen LV, núm. 64. 
KateB, G. (2011). Human Dignity. The Belknap Press of Harvard University.

Leiva Ramírez, E., Torres Santamaría, M., Baquero Urrego, A., GiL Silva, J. (2010). «Violación del libre desarrollo de la personalidad por parte de las Instituciones educativas con relación a la longitud y corte del cabello». Nova et Vétera, Vol. 19, núm. 63.

LUCAS VERDÚ, P. (1984). Estimativa y política constitucionales. Universidad Complutense de Madrid.

Marín Castán, M.L. (2007). "La dignidad humana, los Derechos Humanos y los Derechos Constitucionales».Revista de Bioética y Derecho, núm. 9.

Martínez ZorriLla, D. (2010). Metodología jurídica y argumentación. Madrid: Marcial Pons.

Maslow, A.H. (1982). El hombre autorealizado. Barcelona: Kairós.

Messner, J. (1967). Ética social política y económica a la luz del Derecho Natural (Das Naturrecht. Handbuch der Gesellschaftsethik, Staatsethik und Wirtschaftsethik). Ediciones Rialp.

MoRA, J.E. (2000). «La dignidad de la persona humana en la jurisprudencia constitucional española». Cuadernos de Bioética, núm. 42.

Oehling DE los ReYes, A. (2011). «El concepto constitucional de dignidad de la persona forma de comprensión y modelos predominantes de recepción en la Europa continental». Revista española de derecho constitucional, Año n. ${ }^{\circ}$ 31, núm. 91.

Paredes Montiel, M. (2008). Cuestiones Constitucionales. Revista Mexicana de Derecho Constitucional, núm. 19.

Pascual Lagunas, E. (2009). Configuración jurídica de la dignidad humana en la jurisprudencia del Tribunal Constitucional. Barcelona: Editorial J.M. Bosch.

PelÉ, A. (2006). Filosofía e historia en el fundamento de la dignidad humana. Tesis doctoral en Universidad Carlos III de Madrid. Instituto de Derechos Humanos «Bartolomé de las Casas».

Pereira-Menaut, A.C. y Pereira Sáez, C. (2014). «De nuevo sobre la dignidad humana». Cuadernos de Bioética, Vol. XXV, núm. 84, 2014.

Peters, H. (1963). Das Recht auf freie Entfaltung der Persönlichkeit in der höchstrichterlichen Rechtsprechung. Arbeitsgemeinschaft für Forschung des Landes Nordrhein-Westfalen Geisteswissenschaften, Heft 109, Wiesbaden Springer Fachmedien. 
QuisPe Astoquilca, C.L. (2011). «La interpretación constitucional». Papeles de Teoría y Filosofía del Derecho, núm. 13.

SANTANa Ramos, E.M. (2014). «Las claves interpretativas del libre desarrollo de la personalidad». Cuadernos Electrónicos de Filosofía del Derecho, núm. 29.

Santiago Nino, C. (2003). Introducción al análisis del derecho. Buenos Aires. Astrea.

SchwaBe, J. (2009). Jurisprudencia del Tribunal Constitucional Federal Alemán. Extractos de las sentencias más relevantes compiladas por Jürgen Schwabe.Konrad-Adenauer-Stiftung.

VITERI Custodio, D.D. (2012). «La naturaleza jurídica de la dignidad humana: un análisis comparado de la jurisprudencia del Tribunal Constitucional español y el Tribunal Constitucional Federal alemán». Estudios de Derecho, Vol. 69, núm. 153.

WIENBRACKE, M. (2013). Einführung in die Grundrechte, Wiesbaden, FOM-Edition, Springer Fachmedien, p. 255 (en el capítulo «Allgemeine Handlungsfreiheit, Art. 2 Abs. 1 GG»).

WinTRICH, J.M. (1957). «Zur Problematik der Grundrechte», en Stein, E. Derecho Político (Lehrbuch des Staatsrechts). (1973) (traducción de Sainz Moreno), Madrid: Aguilar.

ZAKARIÁs, K. y BENEKE, K. (2012). «Human dignity in the case-law of the Constitutional Courts of Germany, Hungary and Romania». Buletinul Curţii Constituţionale (The Constitutional Court Bulletin, Romania), núm. 2. 